\title{
Investigating Quaternary glacial relics in Binalod Heights and Their Effects on Site Selection and Development of Mashhad City
}

\author{
Abolghasem Amirahmadi ${ }^{a}$ \\ Professor of Geomorphology, Department of Physical Geography, Faculty of Geography and Environmental
} Science, Hakim Sabzevari University, Sabzevar, Iran

\section{Leila Gholimokhtari a}

Assistant Professor Geomorphology, Department of Physical Geography, Faculty of Geography and Environmental Science, Hakim Sabzevari University, Sabzevar, Iran

\section{Mahnaz Naemitabar a \\ PhD student Geomorphology, Department of Physical Geography, Faculty of Geography and Environmental Science, Hakim Sabzevari University, Sabzevar, Iran}

\begin{abstract}
Mokhtar karami ${ }^{a}$
Assistant Professor Geomorphology, Department of Physical Geography, Faculty of Geography and Environmental Science, Hakim Sabzevari University, Sabzevar, Iran
\end{abstract}

\begin{abstract}
Accordingly, the present study is aimed at investigating quaternary climate changes in Binalod Heights. To identify glacial effects, Morphic indices, field evidence and effects, climatic evidence, and (laboratory) experimental analysis were employed. Determining the permanent snow line in the region was conducted using the Right Method and 65 cirques which are considered as much enriched feeding resources for the formation an ice cover in the region. The expansion of settlements in the region are lower than the permanent snow life is more accumulated than above the border of the permanent snow line. This issue indicates that refrigeration cells do not have the ability to create civil nuclear. Regarding quaternary climate changes and the gradual warming of the climate, the initial core of the City of Mashhad ranges from the center of the Kashf rood River to northeastern heights of Binalod. In addition, the existence of glacial cirques in heights as an important factor in feeding refrigerating conditions has been effective on the expansion of urbanization of Mashhad in the past time. Our new geomorphological mapping and landsystem reconstructions provide an important insight into the response of temperate Binalod glaciers to rapidly-warming climate.
\end{abstract}

Keywords: permanent snow line, Quaternary, Cirque, Glaciers, Binalod

\subsection{Introduction}

Geomorphic processes operating under average Quaternary conditions contributed importantly to landscape evolution. Examples of landscapes that may represent such average conditions include cirques and fluvial deposits. Aarseth etal (1974). The glaciers also contribute to the major rivers in Asia, affecting freshwater supply to billions of people, Xu Peng etal (2018). Glaciers are considered as one of the best short term biological indices of quaternary climate change Ghchev $(2016,12)$. In Iran, most cities are on the

\footnotetext{
a amirahmadi@hsu.ac.ir

a.mokhtari@hsu.ac.ir

amahnaznaemi70@gmail.com

a.karami@hsu.ac.ir

${ }^{1}$ Department of Physical Geography, Faculty of Geography and Environmental Science, Hakim Sabzevari University, Sabzevar, Iran
} 
condensation forms caused by water activity such as alluvial fans, plains and deltas and so far, a lot of studies have been conducted on geomorphological factors threatening as well as their development potentials. But, regarding villages and cities built on glacial geomorphological effects, less attention have been paid by researchers Ramesht $(2000,1)$. There is an undeniable relationship between spatial identity and history of human beings. This issue have caused that a lot of efforts be exerted by researchers for explaining the history of human beings in each place and time and transferring it to the next generation. In this arena, the history of evolution of civil canons of cities is highly important. The natural history of civil canons not only can justify a lot of facts about changes in physical spaces of cities, but also it can complement their history and the social, economic, and political history and evolution Falamaki $(1988,27)$. Identifying and investigating the quaternary period and environmental changes are important because most vital activities such as natural resources, agriculture, and urbanization are founded on the construction of this period. In addition, it covers more than a half of Iran's area. The glacial theory was developed in the early 1830 in the mountains of Western Europe. Jean de Charpentier and Jens Esmark, as well as many other natural scientists, are credited with initial discoveries and development of the concept that glaciers had formerly expanded over larger areas Ramesht (2008). Studies conducted on Iranian glaciers in this period are not many. There are a few studies all are related to recent century Rob et al (1981). Investigating morphological effects of quaternary glaciers in Iran is a subject interested by a lot of researchers. The beginning of this interest can be considered by De Morgan in 1890 Kuffman (1990). Furthermore, the latest research was conducted by Vaziri titled as "primary identification of natural glaciers in Iran" along with some images of Iranian glaciers Vaziri (2003). Najaf Abadi et al (2013) declared that the existence of 99 big and small cirques in the region indicates this issue that the cold glacial period of cirques is one of the main feeding resources. The mode of spatial distribution of villages of Sanandaj accurately follows the movement and formation of glacier tongues. Jeffrey and et al (2011), in investigating climate changes on natural glaciers in Cordillera Blanca, Peru concluded that local residents of this region are highly dependent on water flows caused by seasonal melting of glaciers in this region. Sorg et al (2012) in investigating climate changes on natural glaciers and running water in Tin Shan concluded that natural resources and changes in ice runoff in Tin Shan Mountains is a cause for migration of human beings during communities of history in the region and townships in the Middle Asia and millions of people are still highly dependent on natural glaciers. They have done valuable work on the earliest traces of human life in Iran, and the Fourth Era of climate change, Wright (1963), Vita - Finzi (1977), Professor Ariai A., Thibault (1980). Fredin et al (2013) believe that the current landscape of Norway is the result of geological and geomorphological processes over a very long time. However, much of its current landforms are the result of Quaternary glaciers. Glacial shapes such as circuses, U-shaped valleys, mourn, drumlines and scrolls with sizes of millimeters to kilometers can be seen in Norway. Yasilivert et al (2016) estimated 2,300 meters above sea level in the eastern Turkish Quaternary Coat of Arms with two circus elevation methods and elevation ratios, which was about 800 meters lower than the current border snow height. Brooke and Kirkbride (2018) estimated the altitude of the iconic Tarawa area of the Tarawa region of Iceland for the present conditions at $1200 \mathrm{~m}$, while they believe that during the Quaternary period, this elevation was below sea level and even lower. Mindrasco and Evans (2014) studied circuses and their development in Romania. Delmas etal (2015) studied the allometric growth of circuses in the Alps and analyzed them based on statistical methods. Horton (2004) refers to the human reaction and changes in the level of the Persian Gulf basin in the Holocene and the effects of Persian Gulf water fluctuations on settlements between 3,000 and 6,000 BC and its importance in how the first civilizations in the world were created under The effect of the natural position of the Persian Gulf pit has arisen. A look at the history of the evolution of civil societies around the world shows that the emergence and evolution of civil societies follows a specific law, such that, according to Will Durant's analysis of glaciation reigns on Earth, the civilization shrinkage of sovereignty glaciers. The extension of civilization is mentioned. The result of the dominance of the anaglyshal periods in Iran was the formation of cold civilization and the dominance of the kata glychial period of the formation of the hot civilization, but such an event did not occur in an absolute and theatrical manner but coincided with these exceptions in the Iranian exceptionsWill Durant(1982, 3). Takeuchi and et al (2014) in investigating natural glaciers of Tin Shan in the Central Asia, concluded that a lot of natural glaciers in this 
region are the remainders of the last Ice Age and during thousands of years, they have had roles in supplying vital water resources for local residents. Myglan et al (2014) in investigating glaciers of the southeast Altaic glaciers (in Russia) and their effects on human settlements during past 3000 years concluded that fluctuations of climate glaciers and their changes in the model of evolution and migration has had a great role. Therefore, the present study is aimed at investigating the role of quaternary climate changes particularly changes in permanent snow line and geomorphological changes in the evolution of civilization and the expansion of urbanization in Mashhad City as the case of the study.

\section{2 study area}

Binalod Mountains ranges from latitude 36 degrees 16 minutes north and 59 degrees and 5 minutes east as approximately $130 \mathrm{~km}$ in north of Neishabor to the southwest of Ghochan City, and reaches the northwest of Aladagh Mountains (Continuation of Alborz Mountain). Binalod Mountains is considered as the natural border between Neishaboor and Mashhad. Three permanent rivers of the Kashf-Rood, Atrak, and Kalshour Rivers originate from this mountain. The springs originating from Binalod mostly fall into the Kalshoor River, and the northern ones of this mountain fall into the Kashf-Rood River. In addition to these rivers, there are rivers with relatively less water such as Mir Abad, Zoshk and Torghabeh, Akhelmand, Farizi, Buzhan, Kharv Olia, Bar and Diz Bad Olia in the valleys of this region. This mountain with its cold mountainous weather and high peaks such as Shir Abad, Zargaran, Falsakeh, and Chaman, supplies the water for cities of Mashhad, Neishabor, Chenaran, Golbahar, and its mountainside villages. The area of the region under study is $3095.61 \mathrm{Km}^{2}$ (Fig.1).

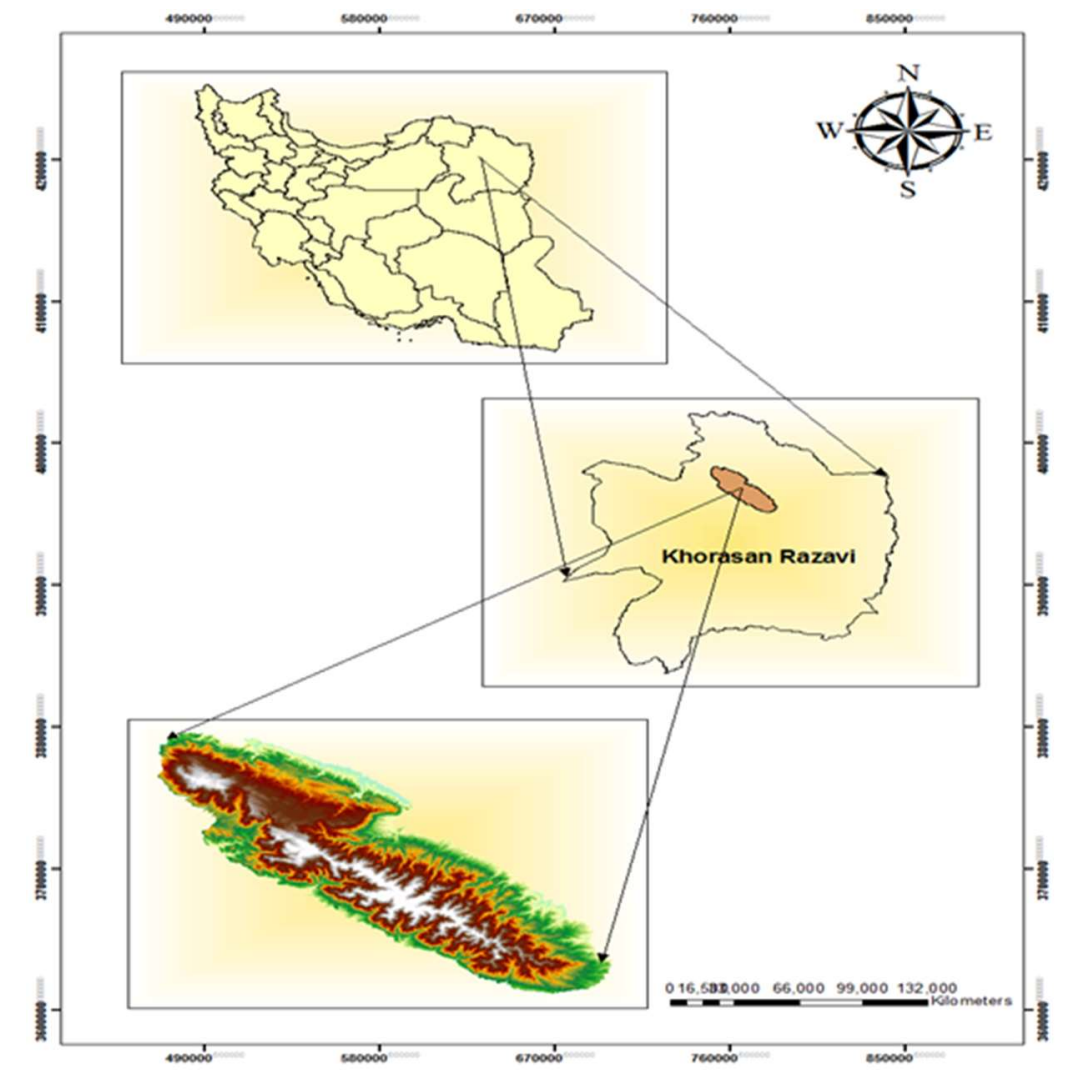

Fig. A. 1 the geographical location of the region under study

\section{Materials and methods}


First of all, the scope under study was identified in the topographic map 1:50000 (Akhelmand, Golmakan, Chenaran, Some'eh, Torghabeh, Piveh Zhan, Ghadamgah, Bozghan, Doghaei, and Kaleidar). Then, geomorphological indices of the region were investigated and using these geomorphological phenomena, quaternary climate conditions were reconstructed. In this method, to determine the environmental consequences of changes, the permanent snow line and the water-ice balance line were determined suing the Write Method. After that, digital reconstruction of temperature values as well as environmental were constructed in order that it was determined what conditions dominated the region in the quaternary period. Then, regarding the satellite images and topographic maps, cirques of the region were extracted. After that, the permanent snow line was determine using the Write Method (the permanent snow line determines for us a height over which there are $60 \%$ of cirques). In other words, in the coldest period dominant over the region, in this height, there has always been snow or in other words, the average temperature on this line there have been as zero degrees Celsius. To draw the temperature and wet conditions of the current and past time, 9 weather station were used (Ghochan, Akhelmand, Neishabor, Mashhad, Fariman, Baghi, Bar, Farizi, and Golmakan). From these 9 stations, 4 stations were inside the scope of the study and 5 were around it (Fig .2).

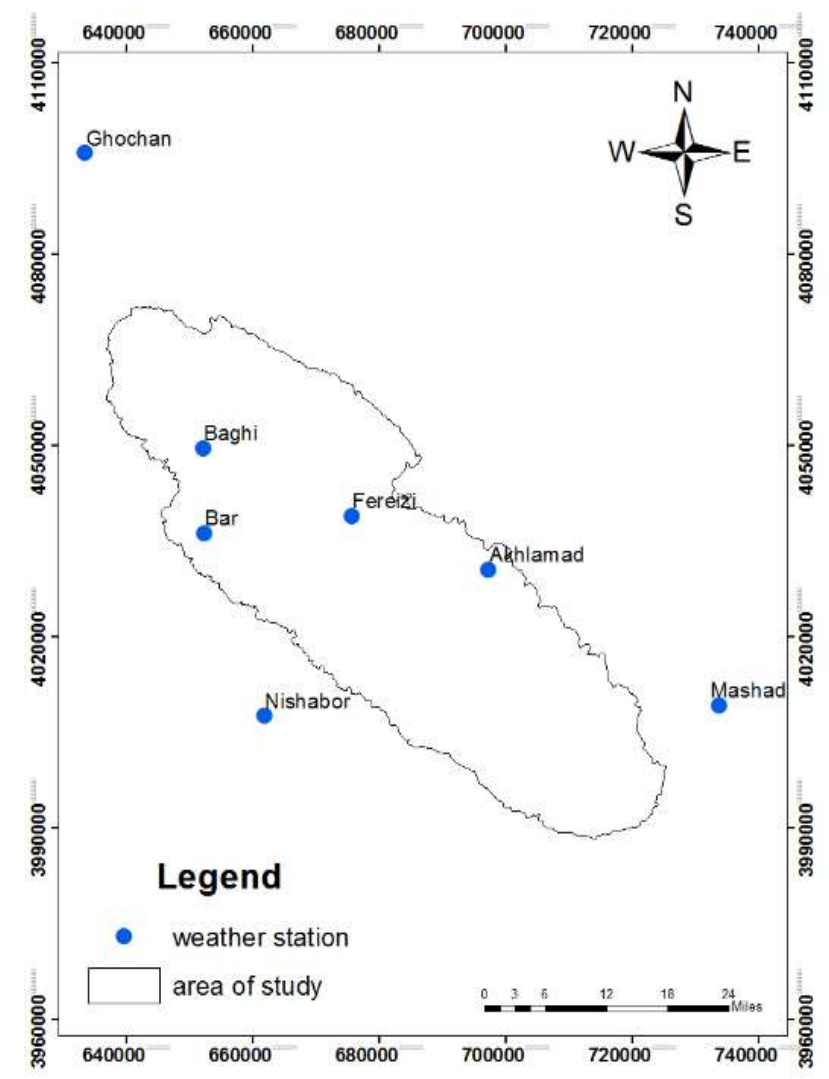

Fig. A. 2 the map of the location of weather stations in the scope of under study

\section{Results}

To identify glacial remainders in the region under study, geomorphological remainders, climate consequences, field evidence, human evidence, and laboratory evidence were used.

\subsection{Geomorphic evidence}

Each glacial cirque is a basin from which mountainous glaciers originate. In other words, the canonical point of feeding glaciers is called a cirque. This effect has been created in the highest part of a valley near 
peaks of mountains in the form of a funnel-shaped hole caused by the ice concentration in a previous pit. Glacial cirques of the region under study are mostly of non-typical kind. That is, they have lost their first primary form in such a way that their undersides have been devastated and is loose and do not have the characteristics of a typical cirque (Fig. 3, 4). The numbered cirques in the region are more than 65 cirques distributed in 2700 to $2800 \mathrm{~m}$ heights of Binalod Heights(table.1). After identifying the circus artefacts using the 1/10000 topographic maps and ETM + satellite images with $20 \mathrm{~m}$ digital resolution, the layer curve lines and the canal layers were estimated by Wright method. The total number of circuses in the study area was multiplied by $60 \%$ and the height of snow boarder was obtained. Using the height of the snow border, the water-ice balance line was also obtained. In Wright's method, by defining the circus location and crossing $60 \%$ of them, the permanent boundary snow is estimated.

Relationship (A. 1):

$\mathrm{R}=\mathrm{n} \times 60 \%$

$\mathrm{R}$ : The number of the circus that is the height of the circus, which is considered the height of the snow boarder (circles that are initially arranged in descending order of height), the number of circuses identified.

Relation 2 was also used to estimate the snow height of the boundary using the Wright method in two stages. In the first step, the maximum height was subtracted from the minimum height, then divided by 100 and multiplied by 60 . From the sum of the numbers obtained from this stage with the lowest circus height identified, the snow height of the boundary was calculated.

Relationship (A. 2):

$X=($ Low circus height - Highest circus height $) / 100 \times 60 \%$

$\mathrm{R}=$ lowest circus height

$\mathrm{X}=$ Difference of snow constant height from the lowest circus height

Permanent boundary snow determination, water and ice balance line, water and land balance line.

Everywhere on the planet, above a certain altitude, precipitation occurs in the form of snow, and this snow remains constant throughout the year. This elevation, called the snow boundary, is subject to change due to changes in annual weather conditions throughout the year. Hence it is called (temporary border snow), while the highest elevation position is called temporary border snow where the snow cover persists throughout the year (permanent border snow) or (permanent border snow). The water-ice equilibrium line is always below the permanent boundary snow line, in other words, ice flows were able to flow hundreds of meters below the permanent snow line during glacial periods fed by upstream snow. Eventually, at a certain height, the ice would cease to move downwards, and from that point onwards, the waterfront area would begin to melt. This boundary is called the water-ice equilibrium

After drawing the curve layer at a distance of $20 \mathrm{~m}$ in the GIS, independent polygons were prepared from the altitudes between 1500 and $1800 \mathrm{~m}$ and their area was calculated. The current water and land balance line height of $95 \mathrm{~km}$ is 1500 meters. If the area of the polygon enclosed in this curve was also $60 \mathrm{~km} \mathrm{2,} \mathrm{then}$ the surface area should be converted to topographic area. The correction factor was obtained from relation (3) and the topographic area of the polygons was estimated.
Relationship (A. 3):
$\mathrm{E}=\mathrm{A} / \mathrm{a}$
$75 \div 60=1 / 25$

E: Error coefficient a: Area of curve obtained by software A: Area of maximum area corresponding to curve of $1500 \mathrm{~m}$.

Using this coefficient, the area of the curve below the elevation of the present drought-water balance line elevation was converted to the topographic area. By comparing the modified zones with the monthly rangearea zones, those monthly zones that had a number close to the elevation zones were selected and the relationship between altitude as an independent variable (x) and area as a dependent variable (Y). Measured. It can be used to estimate the height of the drought equilibrium line in each climatic condition.

$\mathrm{Y}=0 / 260 \mathrm{X}+1372 / 4$

$\mathrm{R}^{2}=0 / 81$ 
Relation (3) is used to estimate the height of the equilibrium water line above the present height. By replacing the estimated ranges for cold Quaternary periods, the equilibrium height of the drought was estimated.

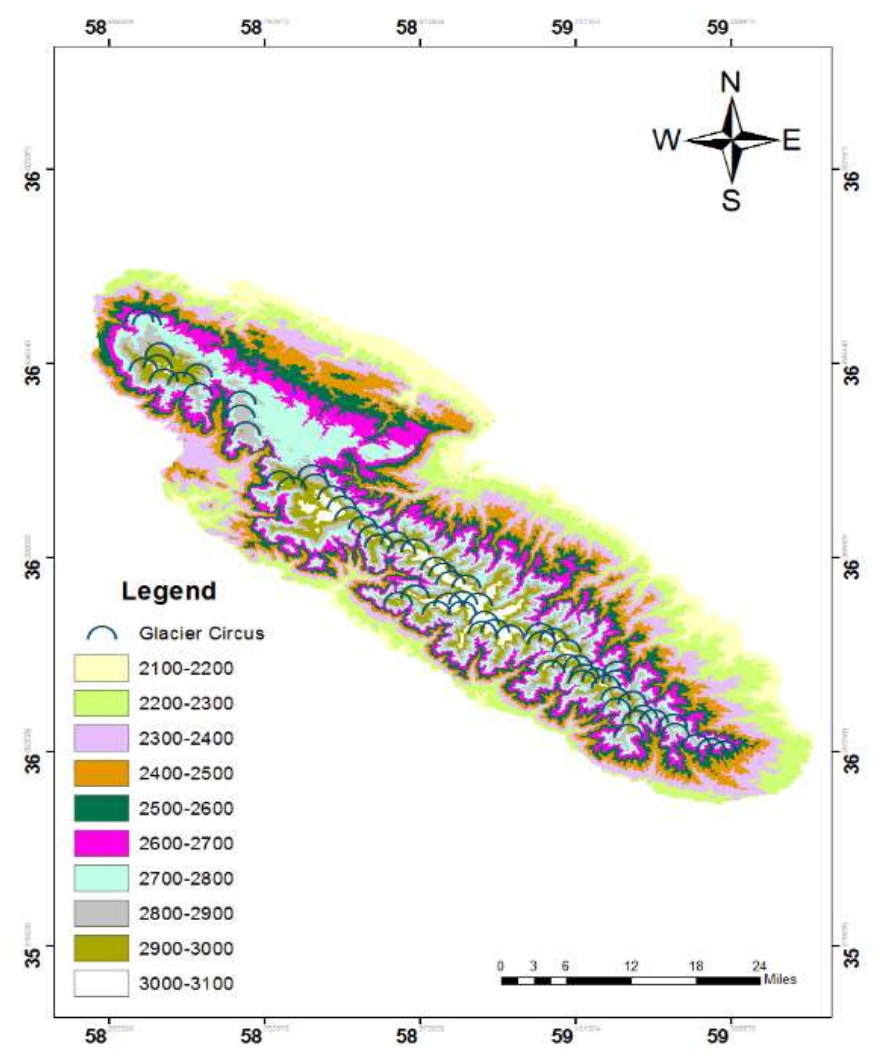

Fig. A.3. the map of locations of cirques of the region under study

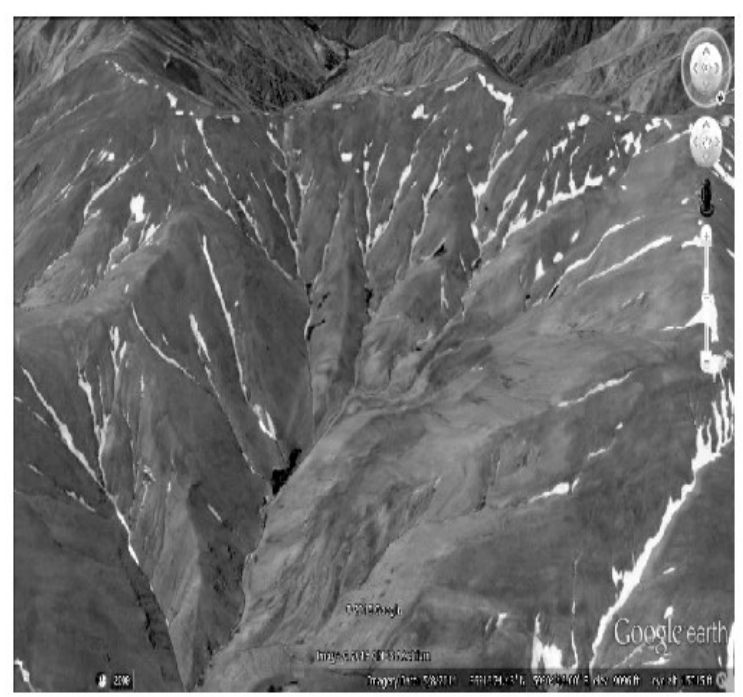

Fig. A.4. The circus heats up on Google Erath

Table A.1. frequency distribute of glacial cirques in the region under study 


\begin{tabular}{|c|c|c|c|c|c|c|c|c|c|c|}
\hline \multirow{2}{*}{$\begin{array}{l}\text { Height } \\
\text { classes }\end{array}$} & \multirow[b]{2}{*}{$\begin{array}{c}\text { Frequen } \\
\text { cy of } \\
\text { cirques }\end{array}$} & \multicolumn{8}{|c|}{ Geographic directions } & \multirow{2}{*}{ Percentag } \\
\hline & & North & $\begin{array}{l}\text { Northe } \\
\text { ast }\end{array}$ & East & $\begin{array}{c}\text { Southea } \\
\text { st }\end{array}$ & South & $\begin{array}{c}\text { Southeas } \\
t\end{array}$ & West & $\begin{array}{c}\text { Northwe } \\
\text { st }\end{array}$ & \\
\hline $2100-2200$ & - & - & - & - & - & - & - & - & - & 0 \\
\hline $2200-2300$ & 2 & - & - & - & - & - & 1 & - & - & 1.53 \\
\hline $2300-2400$ & 4 & - & 2 & - & 2 & - & - & - & - & 6.15 \\
\hline $2400-2500$ & 8 & 2 & 3 & 1 & 1 & 1 & - & - & - & 12.3 \\
\hline $2500-2600$ & 2 & 1 & 2 & - & - & 4 & 1 & 1 & - & 13.8 \\
\hline $2600-2700$ & 20 & 3 & 10 & 1 & - & 2 & - & 1 & 1 & 27.69 \\
\hline $2700-2800$ & 13 & - & 4 & - & - & 4 & 2 & - & 2 & 18.46 \\
\hline $2800-2900$ & 6 & - & 2 & 1 & - & 1 & - & 1 & 1 & 10.7 \\
\hline $2900-3000$ & 1 & 2 & - & 1 & - & - & - & - & - & 4.61 \\
\hline $3000-3100$ & 4 & 2 & 2 & - & 1 & - & - & - & - & 7.69 \\
\hline Total & 65 & 9 & 25 & 4 & 4 & 12 & 4 & 3 & 4 & 100 \\
\hline
\end{tabular}

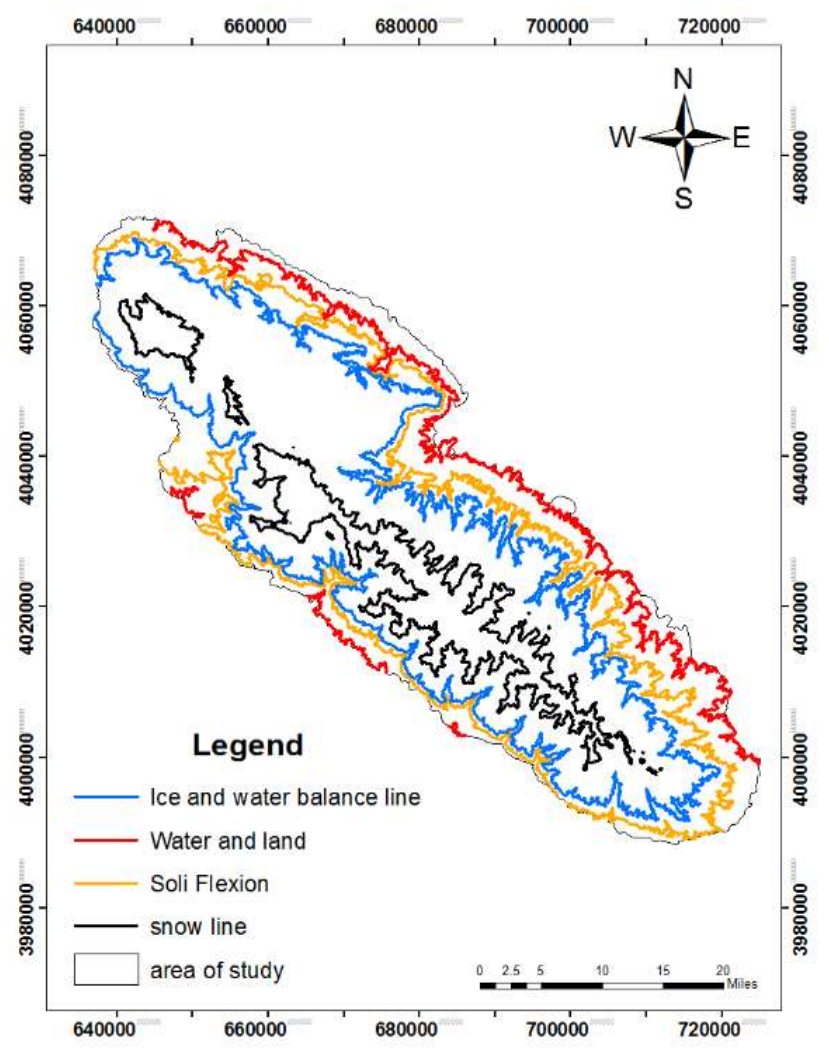


Fig. A.5. Permanent snow line map, water and ice balance line, water and land and Solar Flexon

\section{Discussion}

\section{Estimating permanent snow line in Pleistocene using the Write Method}

Studying cirques existing in the region by the Write Method makes the determination of permanent snow line in the glacial period possible. The permanent snow line determines a height higher than which $60 \%$ of cirques are located. This line indicates the $2543 \mathrm{~m}$ in the Pleistocene period in the region(Fig.5).

\subsection{Impact of Climate Change in Glaciers}

Temperature

Various analyses of temperature pattern in Binalod have shown that the high altitude mountains are highly affected by warming climate as compared to the lower altitude terrains.

Meteorology, for the years between 1996 and 2014 were analyzed to observe the temperature trend in Binalod. The annual average temperature between 1996 and 2014 shows fairly an increasing trend. The total increase in temperature is $7^{\circ} \mathrm{C}$.

\subsection{Data Analysis}

Temperature data of the obtained from the Department of Hydrology and Meteorology, for the years between 1998 and 2014 were analyzed to observe the temperature The annual average temperature between 1998 and 2014 shows fairly an increasing trend (Fig.6, 7, 8, 9, 10, 11, 12).

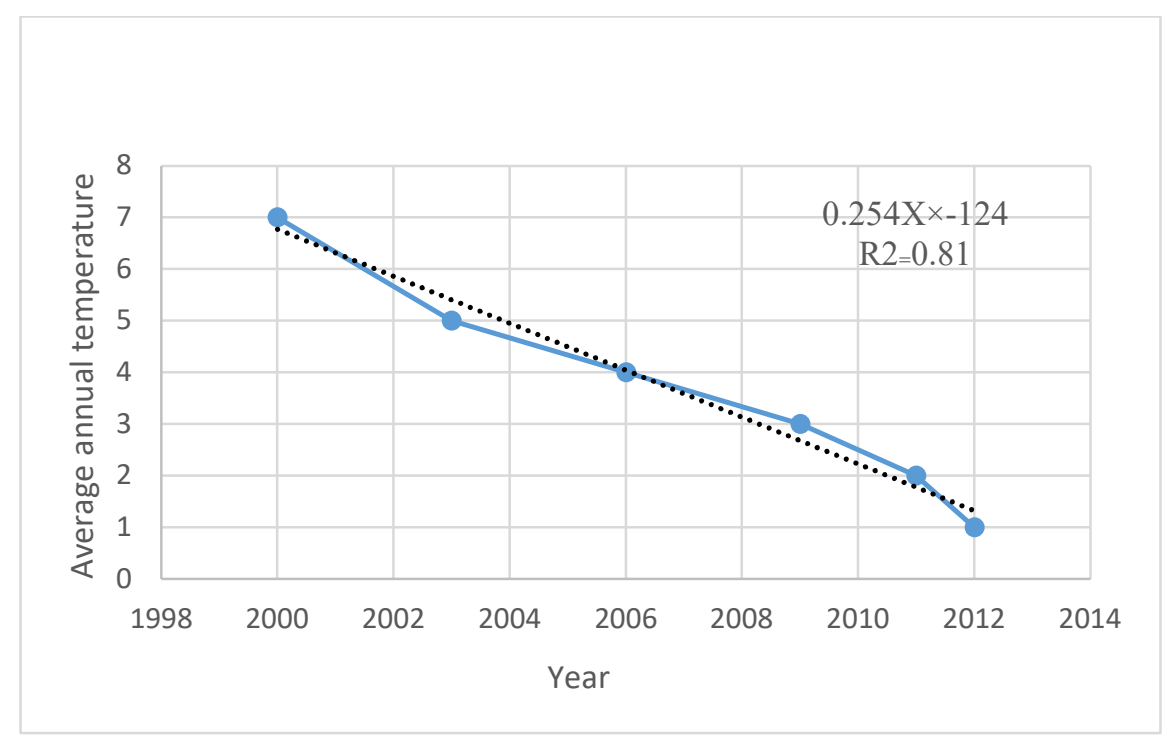

Fig. A.6. Variation of average annual temperature in the between the years 1998 and 2014 


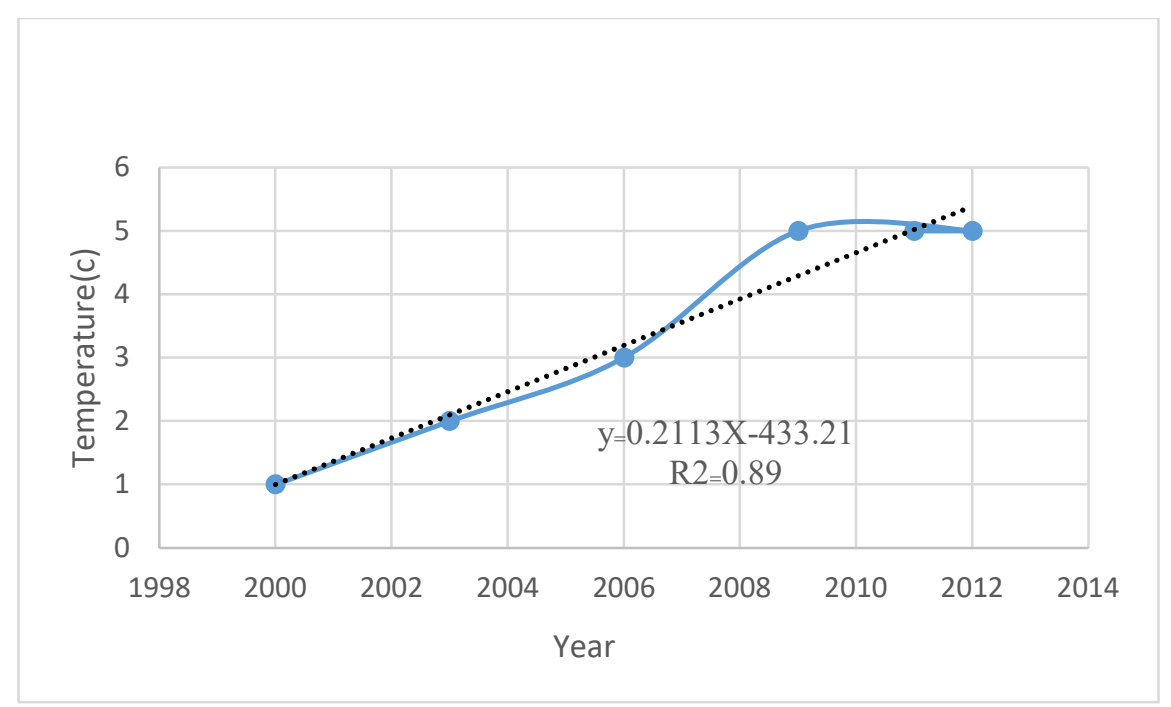

Fig. A.7. Variation of average temperature in the area between 1998 and 2014

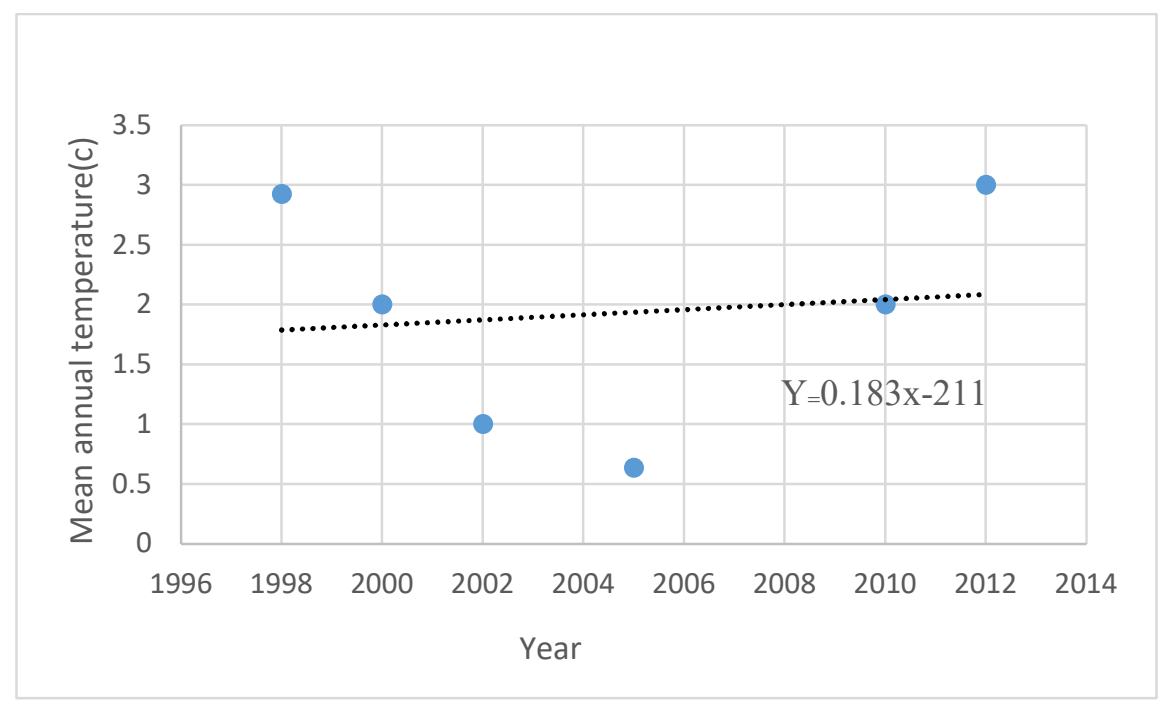

Fig. A.8. Variation of average annual temperature in the from 1996 to 2014 


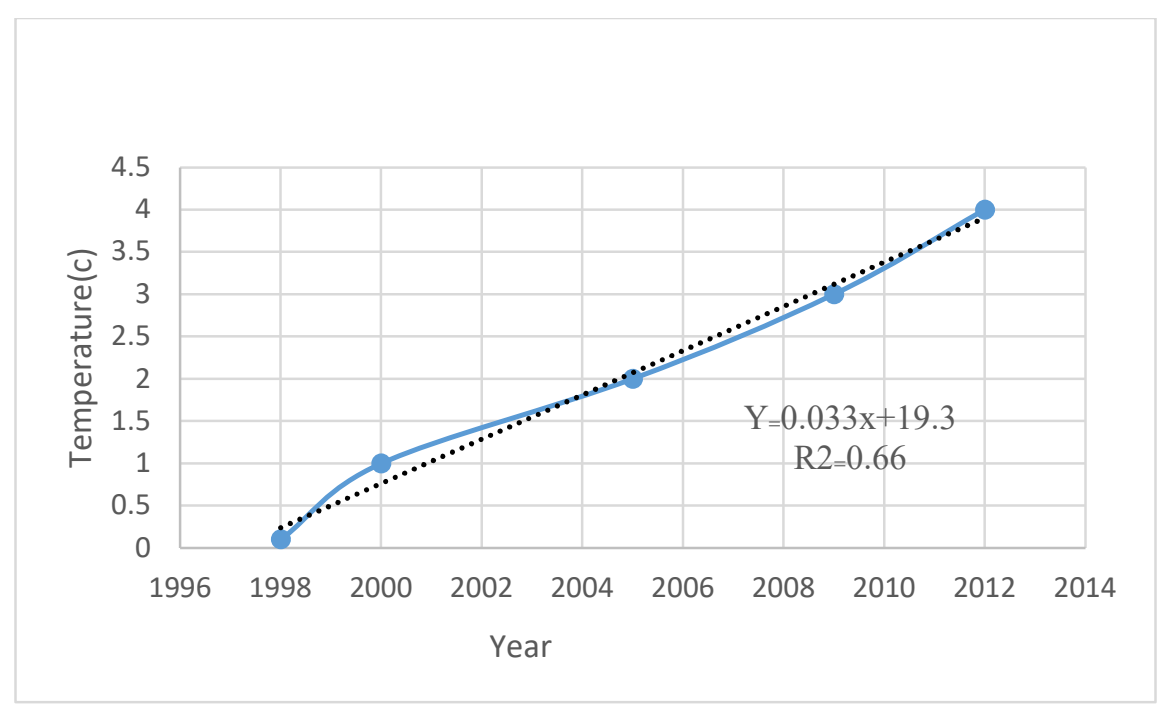

Fig. A.9. Variation of maximum temperature (Tmax), lower section of the between the years 1996 and 2014

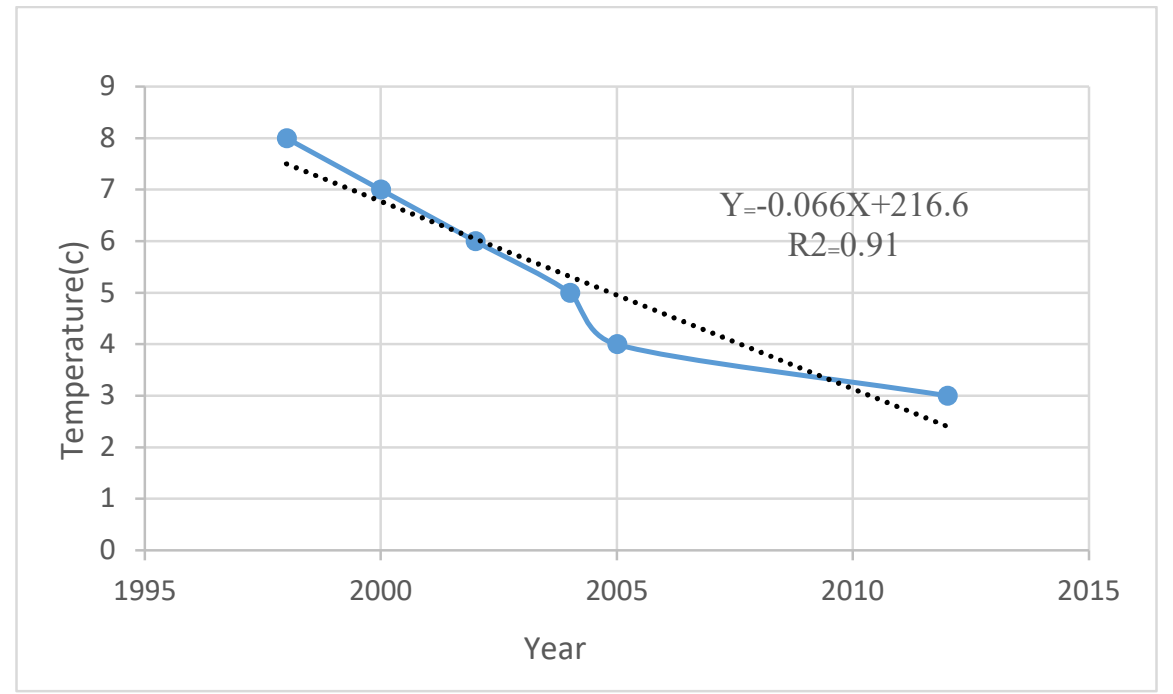

Fig. A.10. Variation of minimum temperature (Tmin) between the years 1995 and 2014 


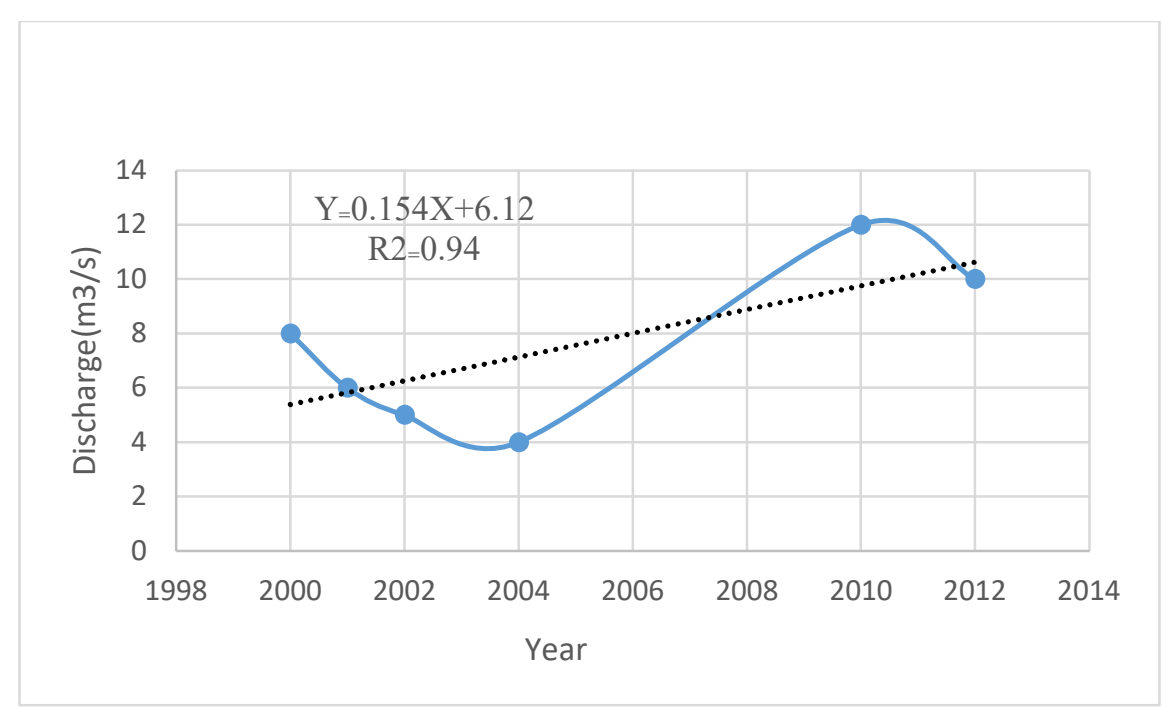

Fig. A.11. Variation of discharge in the from1998 to 2014

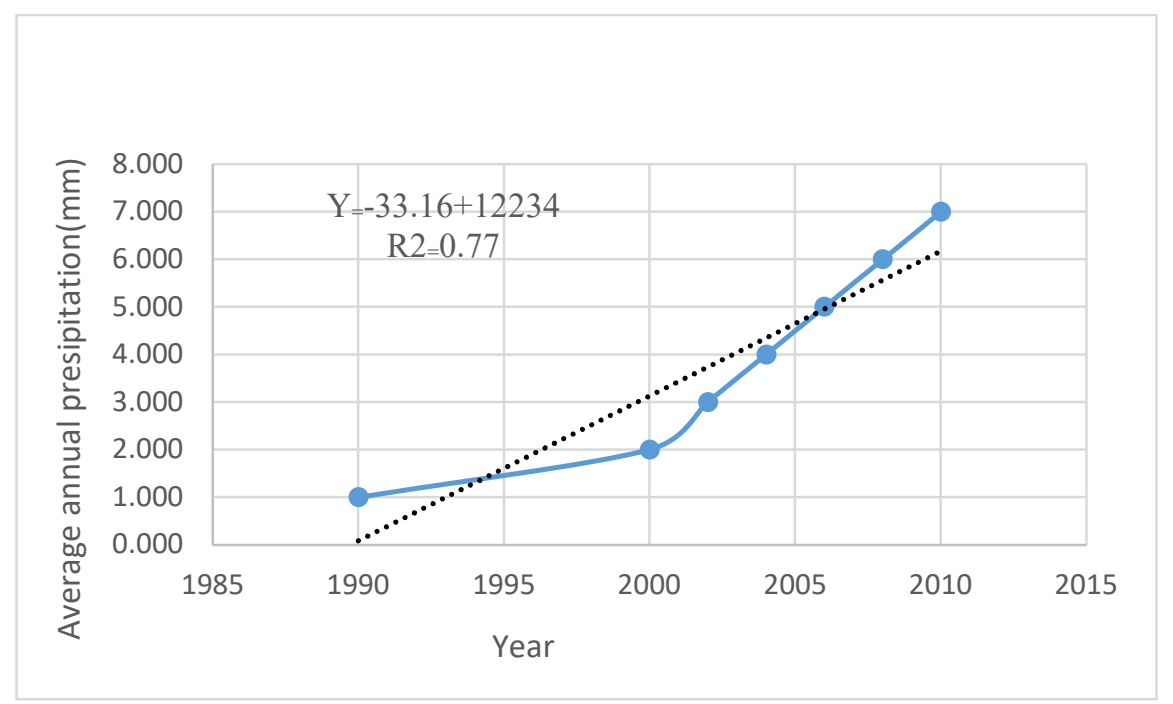

Fig. A.12. Variation of annual precipitation in the between 1985 and 2014

\subsection{Investigating current temperature conditions of the region}

To draw the isothermal map of the scope under study with considering two parameters of height and temperature in stations of the region, the correlation coefficient and then the regression equation of temperature-height were calculated using the Excel software and its linear equation was obtained as $\mathrm{y}=\mathrm{-}$ $0.0048 \mathrm{x}+19.37$. Then, using this equation, the of adiabatic decline of the current temperature of the region was calculated as $5 \mathrm{C}^{\circ}$ per each $1000 \mathrm{~m}$ of spatial promotion(Fig.13). 


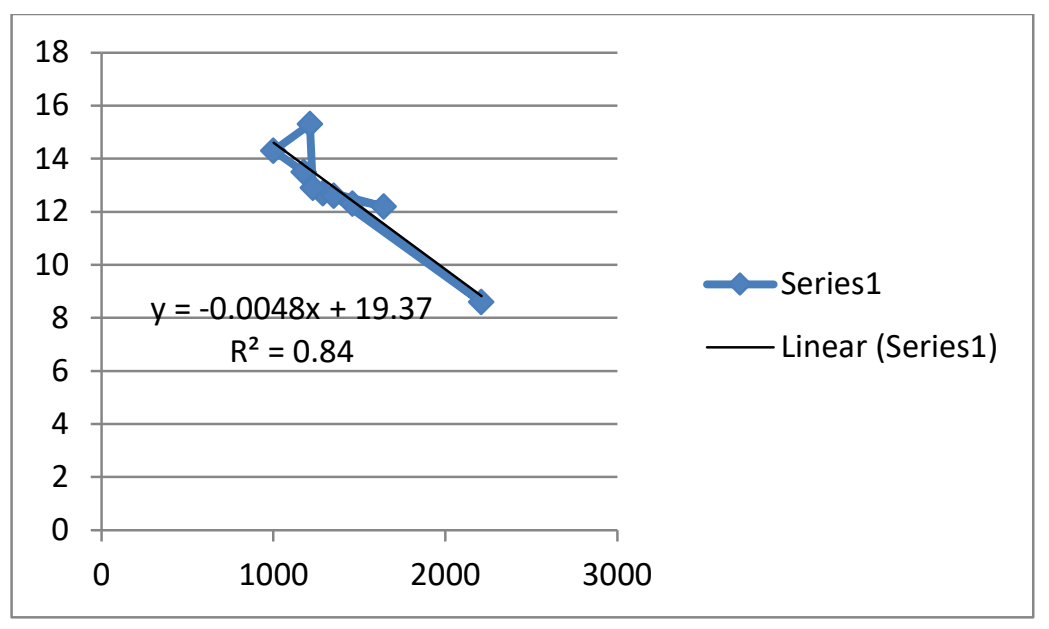

Fig. A.13. Relationship between temperature and Height

After obtaining the above equation, using topographic map, the isothermal map of the scope under study was drawn. The current isothermal map indicates that the minimum temperature of the region in the current time is $3 \mathrm{C}^{\circ}$ and the maximum temperature is $13 \mathrm{C}^{\circ}$ (Fig.14).

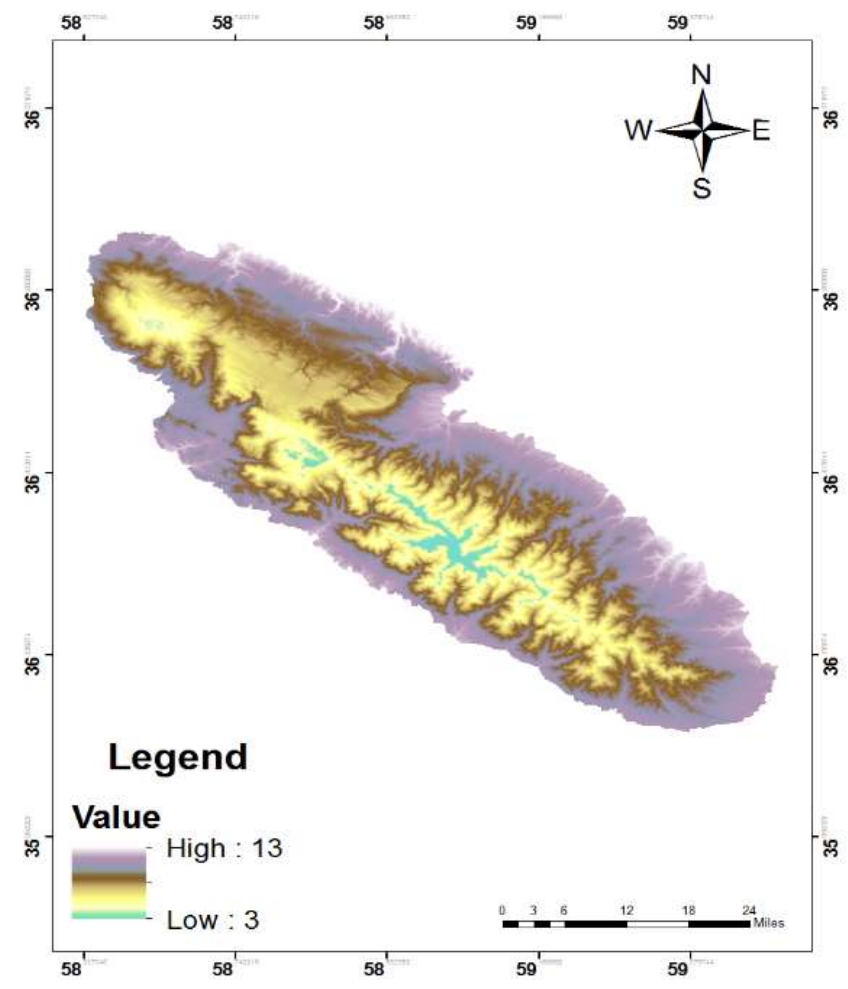

Fig. A.14 the isothermal map of the current time

\subsection{Investigating and reconstructing Pleistocene temperature conditions}

To estimate the past environmental temperature, after the determination of the permanent snow line of the region (as $2543 \mathrm{~m}$ determined by the Write Method) the correlation of temperature and height was calculated. The results indicate that highest correlation is consistent with the linear equation $y=a+b x$ and the decline in temperature per each $1000 \mathrm{~m}$ was obtained as $5 \mathrm{C}^{\circ}$. Regarding the height of the permanent snow lien $(2543 \mathrm{~m})$, the annual temperature line was calculated as zero and regarding the changes in the 
height of the region, the isothermal lines of the past time can be calculated. The minimum temperature at the domination of glaciers was as $-3 \mathrm{C}^{\circ}$ and the maximum was as $6 \mathrm{C}^{\circ}$ (Fig. 15).

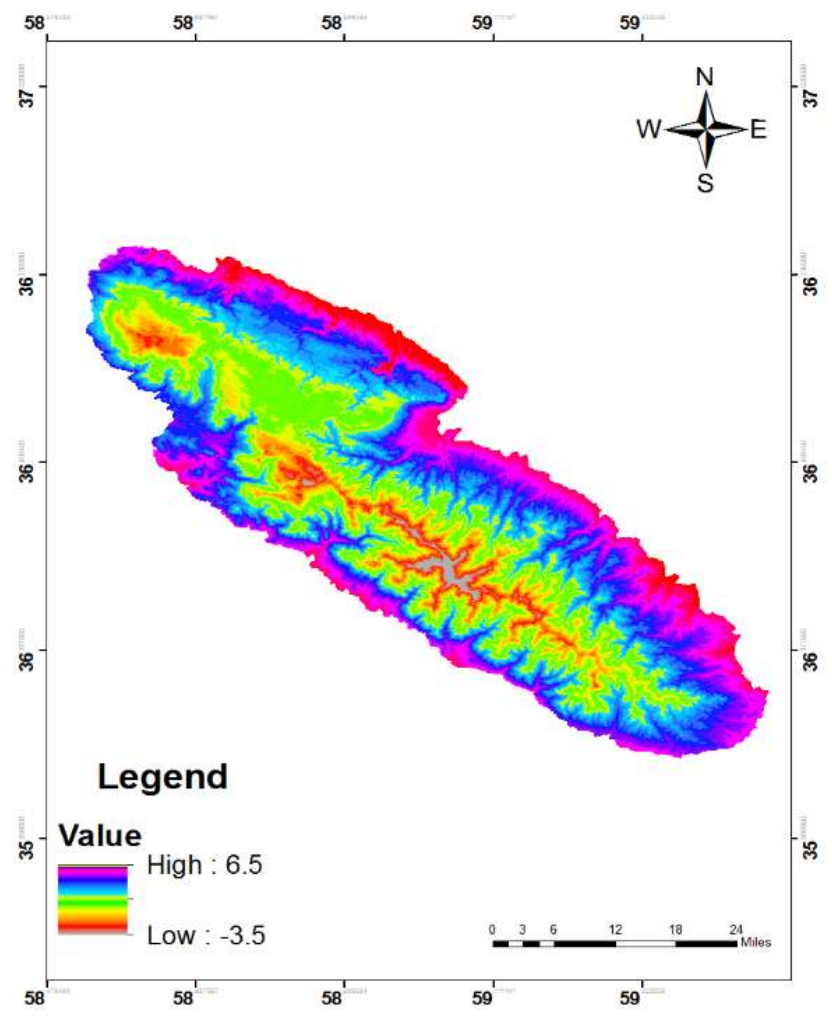

Fig. A.15. the map of isothermal map of Pleistocene periods

\subsection{The difference of temperature of the current time with Pleistocene periods}

For investigating the temperature difference of the current time and the time of glaciers' domination over the region, the isothermal map of the present time and the Pleistocene period were compared and the map of temperature difference of the region was drawn. As observed in the map, the environmental temperature difference of the past and current periods of time was estimated as $7 \mathrm{C}$ and in the region under study, the temperature of the past period of time was $7 \mathrm{C}$ colder than the current time(Fig.16). 


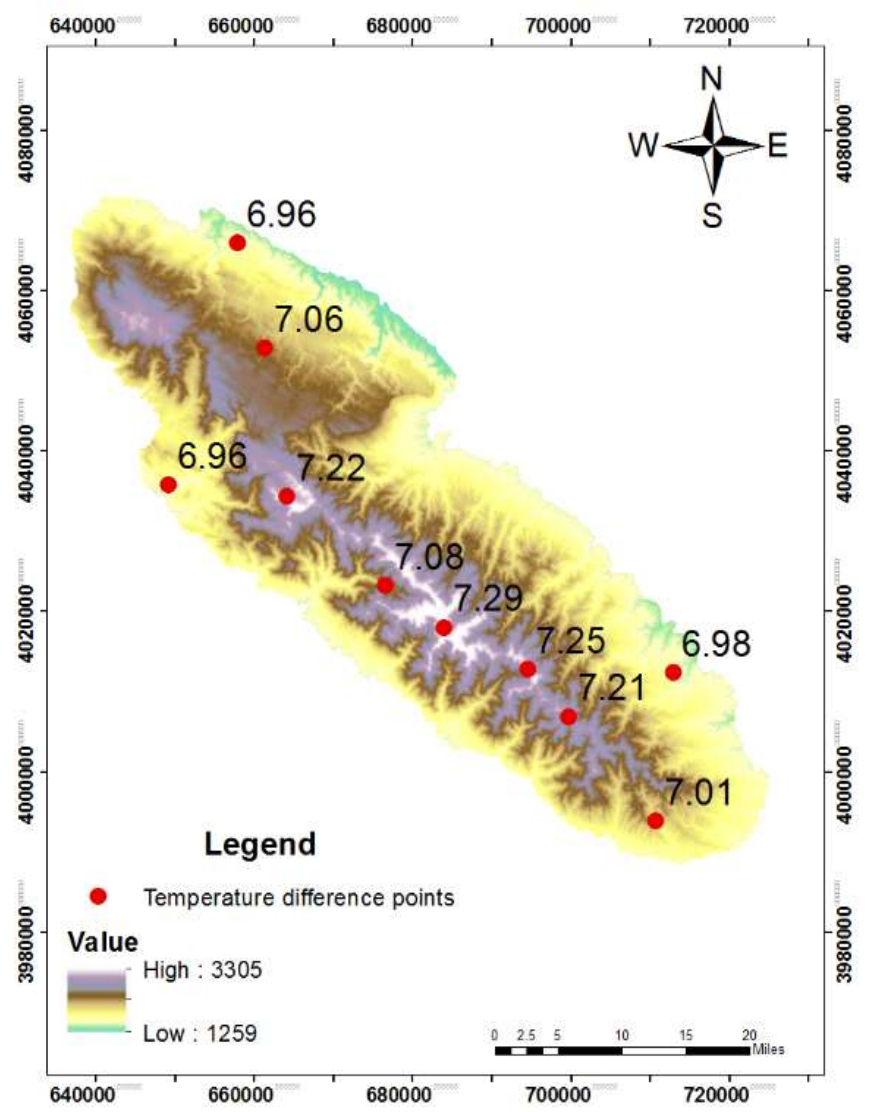

Fig. A.16. the map of the difference of temperature of the current period of time and Pleistocene period in the region under study

\subsection{Investigation of moisture conditions of the region under study}

For investigation of the moisture conditions of the region at the present time the precipitation data of 9 stations of Ghochan, Akhelmad, Neishbor, Mashhad, Fariman, Baghi, Bar, Farizi, and Golmakan were sued. The relationship between height and precipitation was calculated by Excel software and the isorain map of the present time was prepared(Fig.17). The isorain map of the current period of time of the region indicates that minimum precipitation of the region is as $268 \mathrm{~mm}$ and maximum precipitation is as $504 \mathrm{~mm}$ in the highest part of the region. 


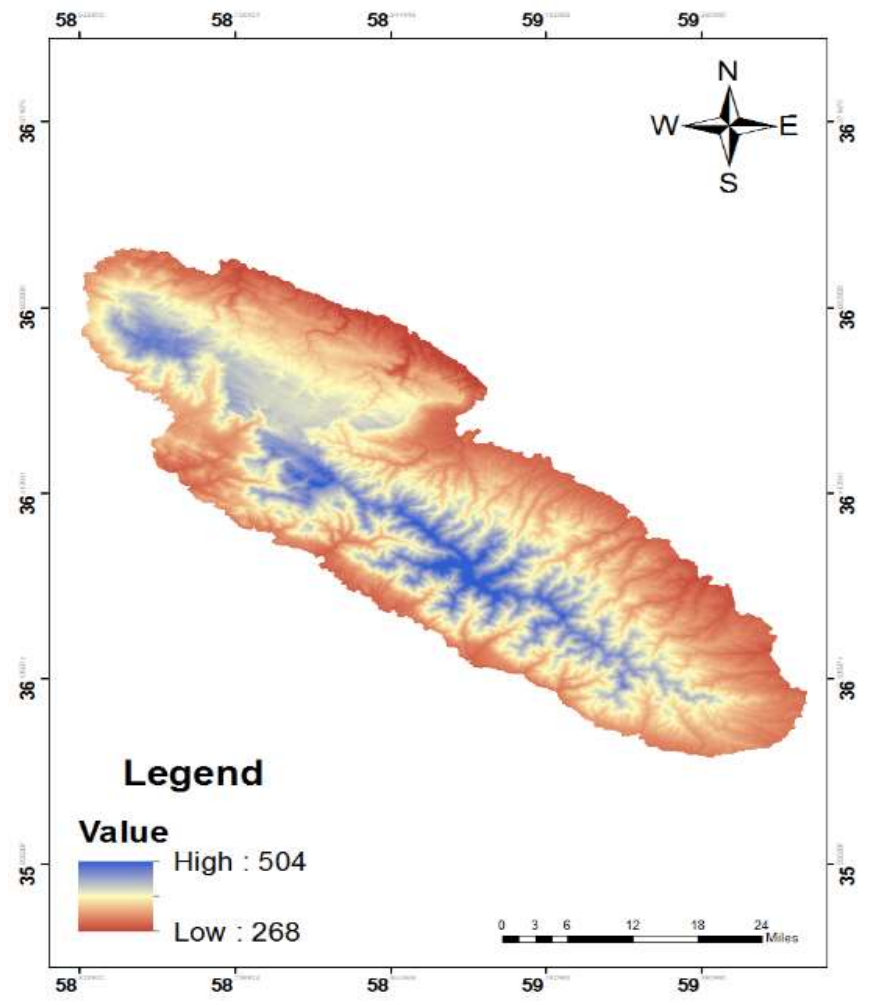

Fig. A.17. the isorain map of the current period of time

\subsection{Investigating moisture conditions of the region in Pleistocene periods}

After overlapping isorain and isothermal maps and regarding the linear equation $y=0.1153 \mathrm{X}+123.25$, the relationship between precipitation and temperature was calculated and regarding the significance of the correlation of temperature and precipitation as well as the stability of the relationship of temperature and precipitation, by having the data of the temperature of the past time, the isorain map of the region in the domination period of glaciers was prepared(Fig.18). The isorain map of the region in the quaternary period indicates that minimum precipitation at that time is equal $430 \mathrm{~mm}$ and maximum precipitation is $630 \mathrm{~mm}$ in the highest part of the region. Comparing isorain maps of the current time and the past time indicates that the amount of environmental humidity in the period of time when the temperature of the environment was $7 \mathrm{C}^{\circ}$ lower has significant difference with the amount of current precipitation. 


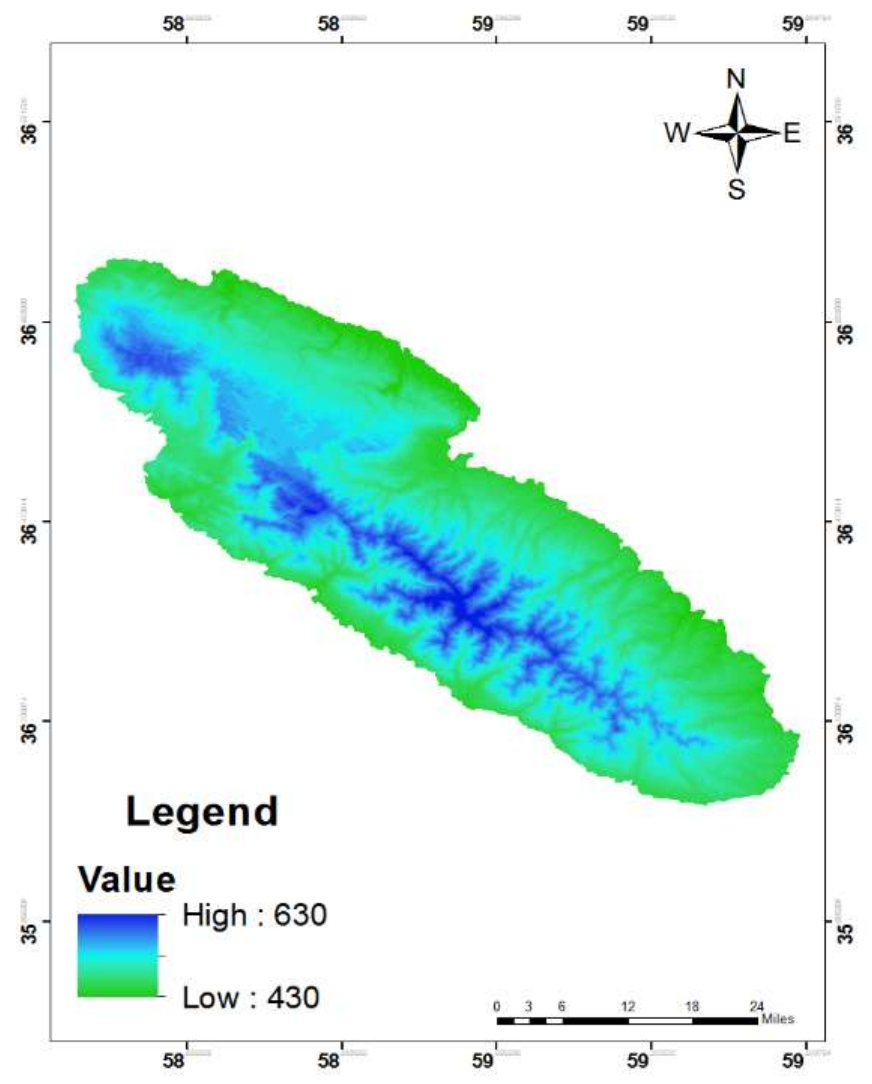

Fig. A.18. the isorain map of Pleistocene periods

\subsection{Field evidence of glacial cold periods in the region}

In the northern heights of the region, some glacial cirques can be observed. These cirques have saved snow in the quaternary period and its evidence is observed clearly(Fig.19). Among other pieces of evidence indicating the existence of glaciers in this region one can refer to glacial moraines, tills, and tours existing with regard to field observation in heights higher than $2000 \mathrm{~m}$.

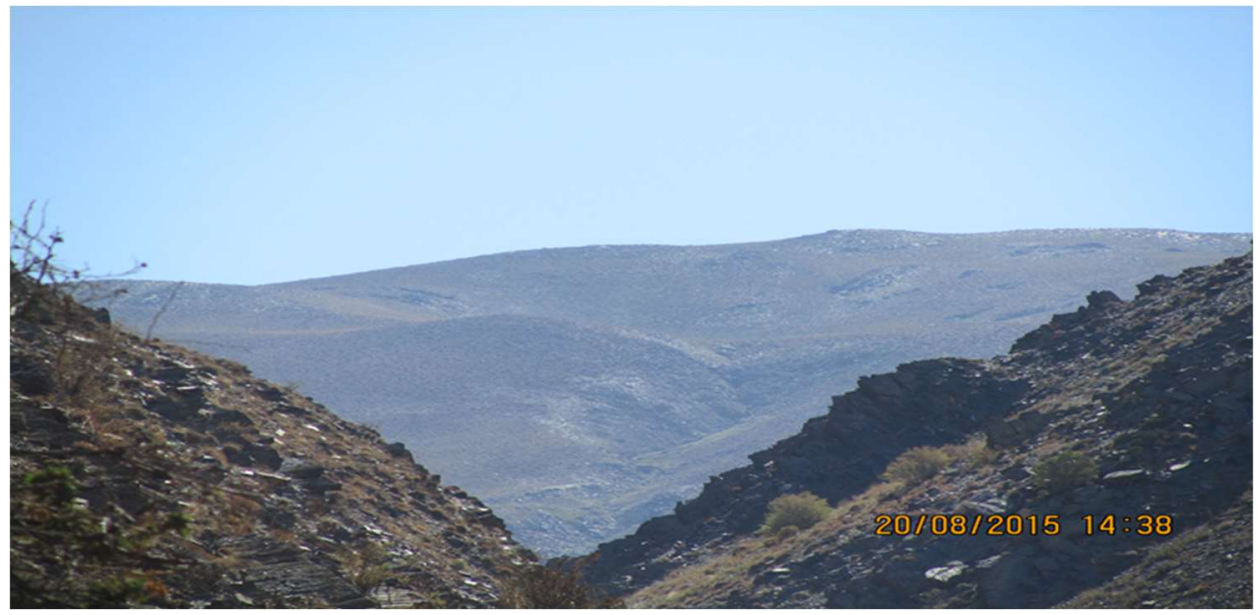

Fig. A.19. a view of the glacier cirque in the region

\subsection{Moraine}


Moraine refers to the glacial disordered and unclassified sediments. Materials of these sediments have a lot of differences in terms of dimensions, grains, and parts and there is no order among them. In fact, it lacks homogeneity. The size of these sediments changes from very large rocks to clay(Amir Ahmadi 2014. 154). In the region under study, moraine can be observed in glacial valleys in the $2300 \mathrm{~m}$ heights(Fig.20). A cluster of moraines in the upper Binalod valley also date to the ACR at $12.6 \pm 0.1 \mathrm{ka}$. Finally, a midHolocene moraine in the upper Binalod valley is dated to $4.3 \pm 0.1 \mathrm{ka}$.

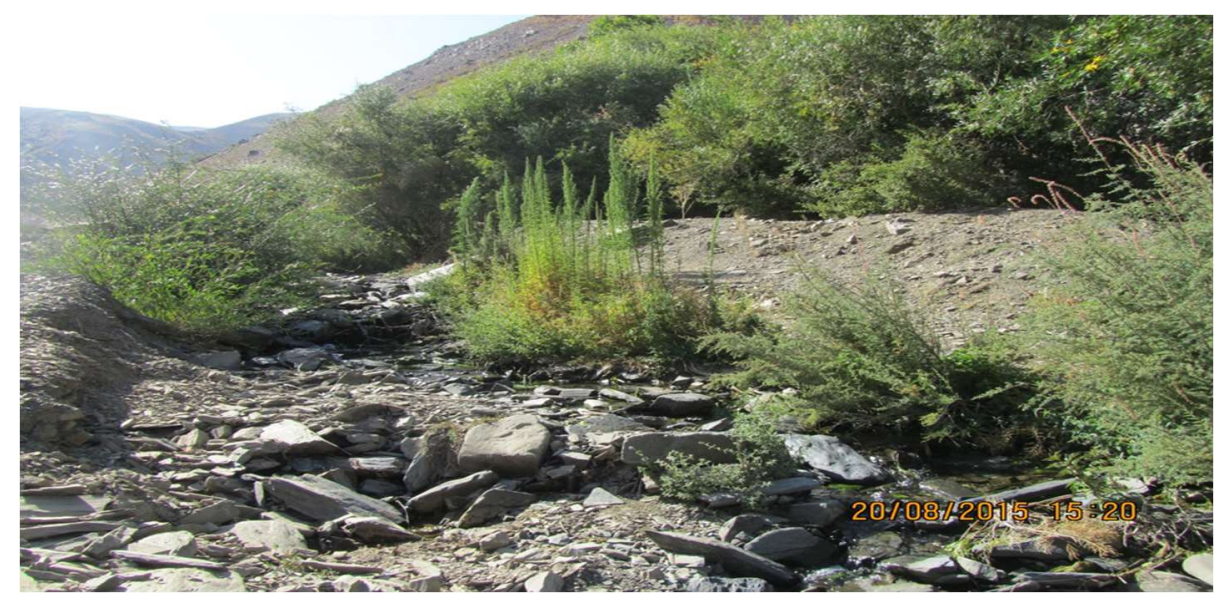

Fig. A.20. a view of a glacial moraine in the region

\subsection{Till}

Refers to disordered glacial sediments produced by the deposit of glacial materials and are medium-grained and without any order in grains. In addition, among them, un-eroded minerals are abundant. Secondly, coarse-grained sediments are found only in points which are the origin of granite and syenite rocks which are striated and angled (Motamed 2003. 70). Glacial tills in the region are observed in heights higher than $2000 \mathrm{~m}$ (Fig.21).

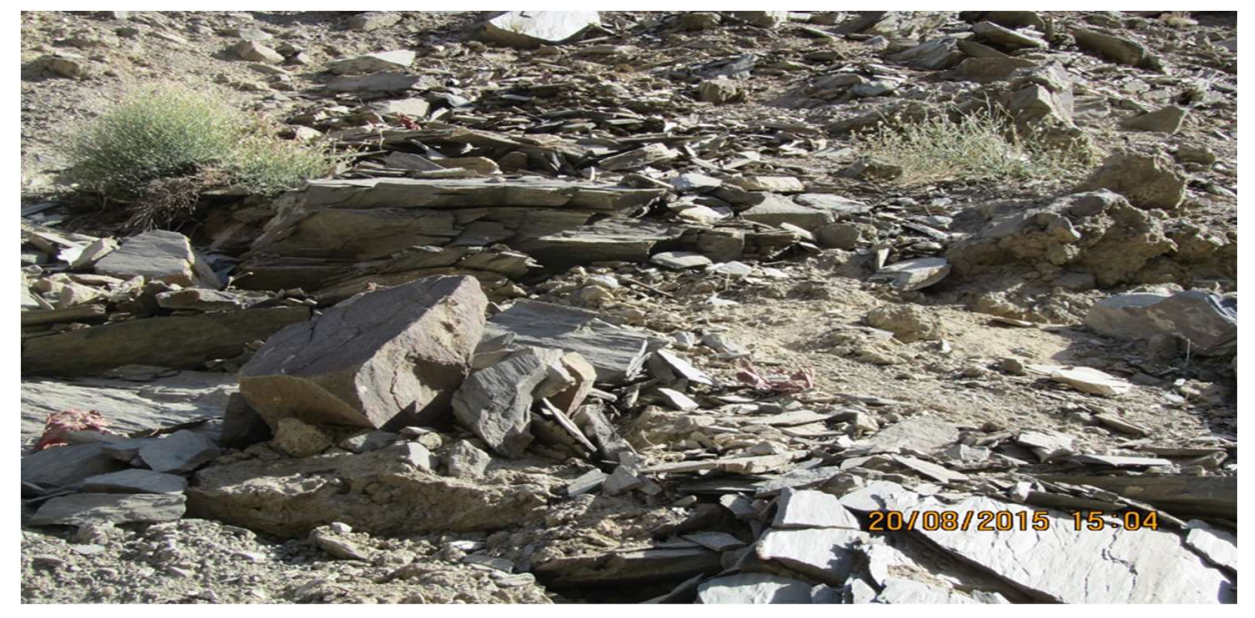

Fig. A.21. a view of glacier tills in the region

\subsection{Glacial tours}

Tours are the results of large rock which are accumulated on domains due to weathering and range erosion processes (Al-Moddaresi. 2005). This phenomenon indicates the near-glacial processes in past periods of time. Glacial tours are constructed due to the erosion performance of the quaternary. Tours are observed in 2000 to $2400 \mathrm{~m}$ heights in the region under study(Fig.22). 


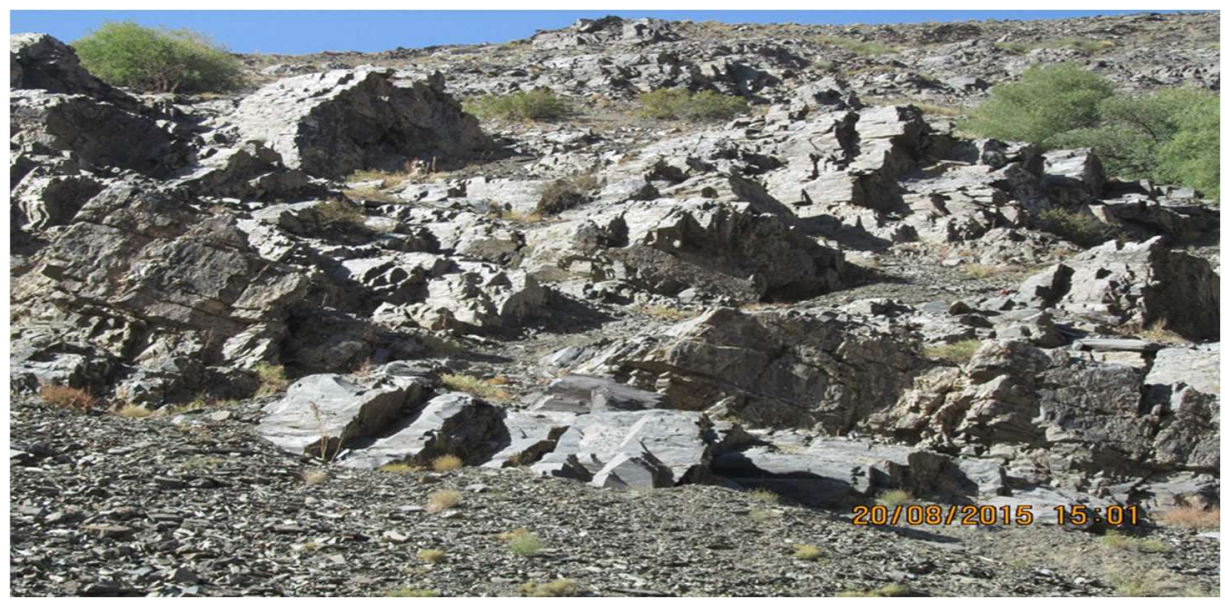

Fig. A.22. a view of glacial tours in the region

\subsection{Human evidence}

\subsubsection{Dispersion of settlements in the region}

In most mountainous areas between the fall of glacier tongues and the entry of glacial cirques, there remains a strip of integrated nodes or effects remaining from glacial lakes on which up-country villages and towns have been constructed. The spatial distribution of these villages follows the movement and formation of glacier tongues. The exemplar of these villages in Yazd Province is Deh Bala, in Natanz is Oreh, and in Loot Desert is Sirch Village (Ramesht. 2002). Settlements existing in the region are located around mountainous heights and the snow line and have not much development in heights higher than $2500 \mathrm{~m}$ due to coldness. Lower than the snow line, due to the gradual melting of glacial cirque and the influence of these effects on feeding water resources, the development of settlement is significant (Fig. 23). 


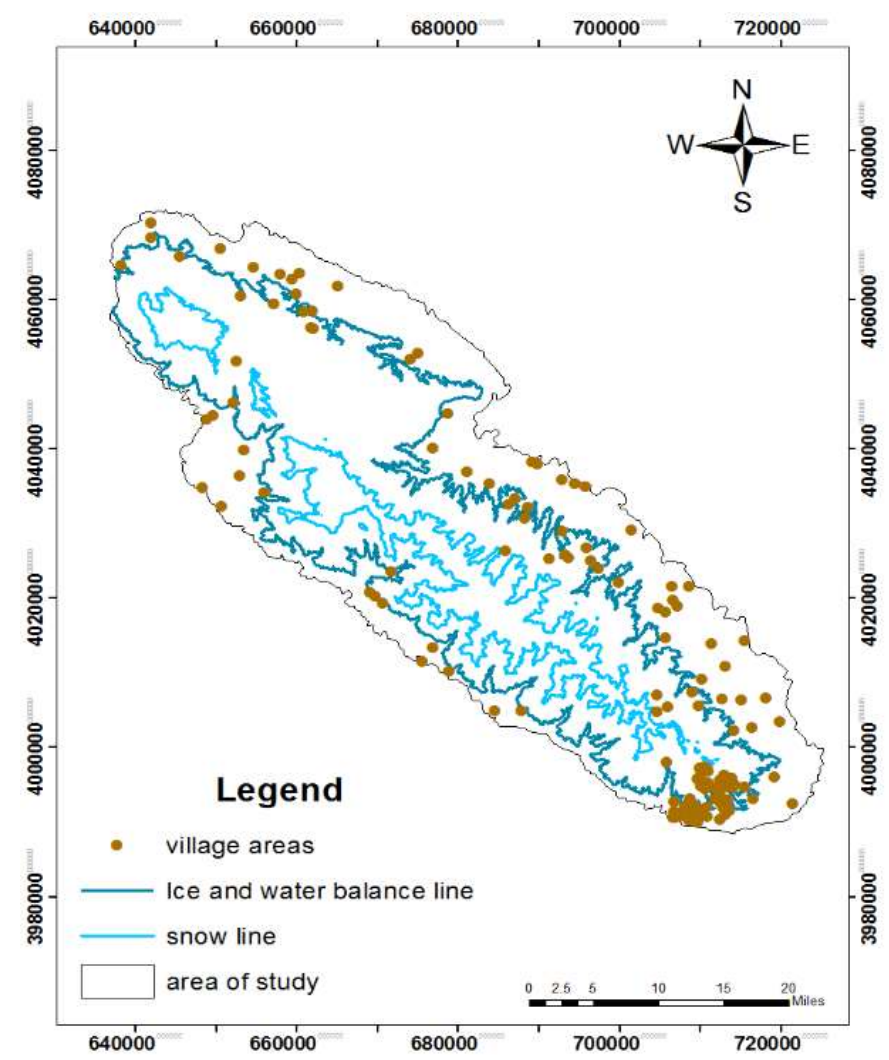

Fig. A.23. the map of distribution of settlements in the region under study

\subsubsection{Local people's observation}

Local people at area were also interviewd to elicit their views about changing pattern of glaciers in their localities for the period during the recent years. On the basis of their observation and their experience, the area covered by ice a decade ago is now converted into a barren land with a rapid retreat of glaciers. They also explained that they feel that summer is getting hotter and winter is warmer than in the past. The duration of winter is shrinking and extremely cold days are decreasing in number. The precipitation rate in the summer is decreasing. The water resources are being dried The local people believe now that if such a rate of glacial melting continues, there will be no more glaciers at all in the near future.

\subsubsection{Laboratory evidence}

In proving the existence of glacial evidence, resorting to laboratory methods especially in studying sediments is conventional Rameshst et al (2011). In the present study, to test the accuracy of analytical and formic findings, and to confirm the existence of glaciers in the region, experiments were conducted on samples(Fig 24, 25, 26, 27,28). 


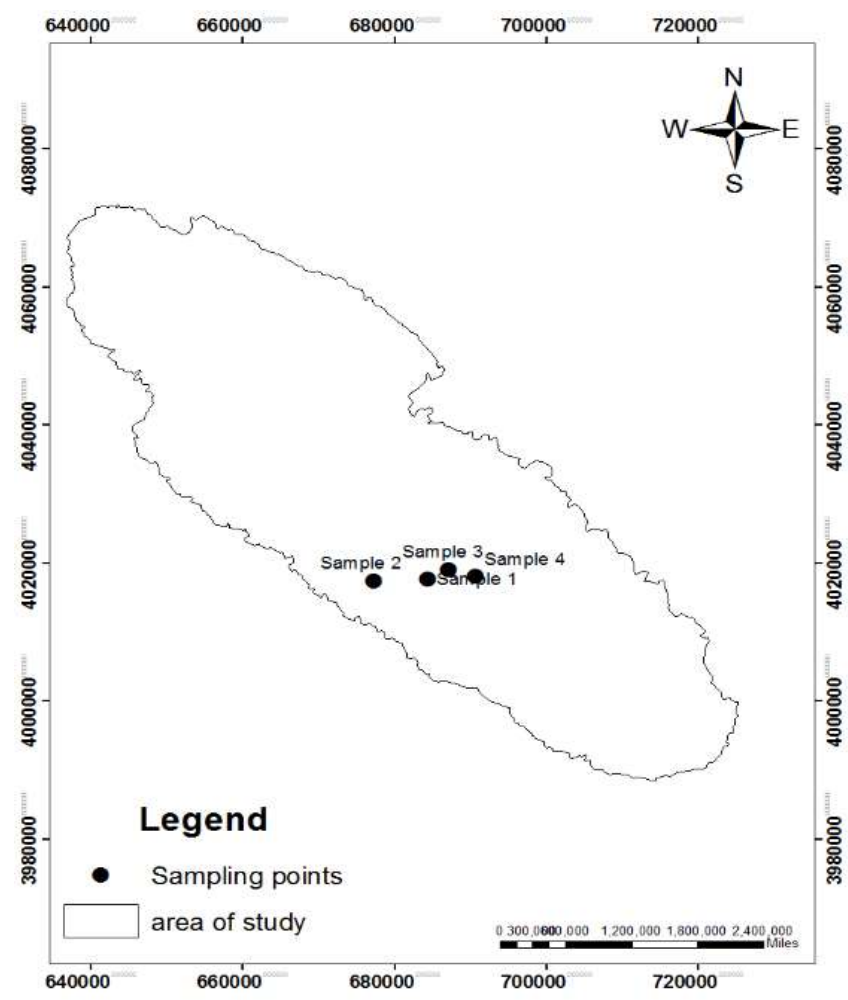

Fig. A.24. Map of sampled points of area

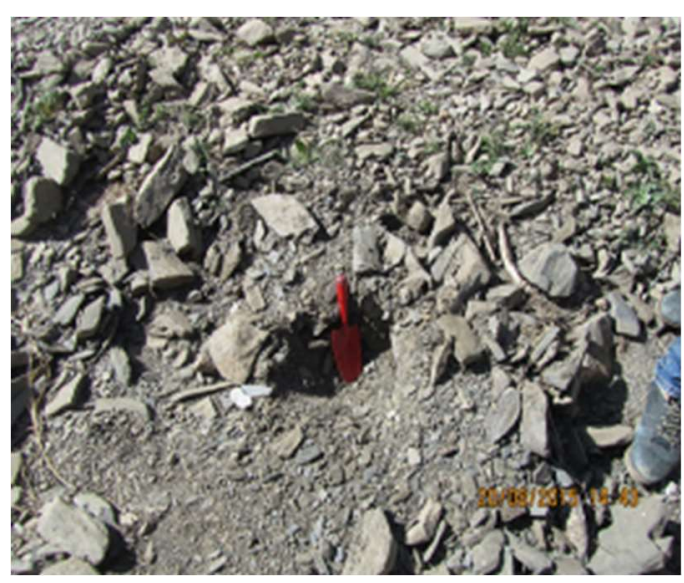

Fig. A.25. Refrigerated sediment sampled No. 1

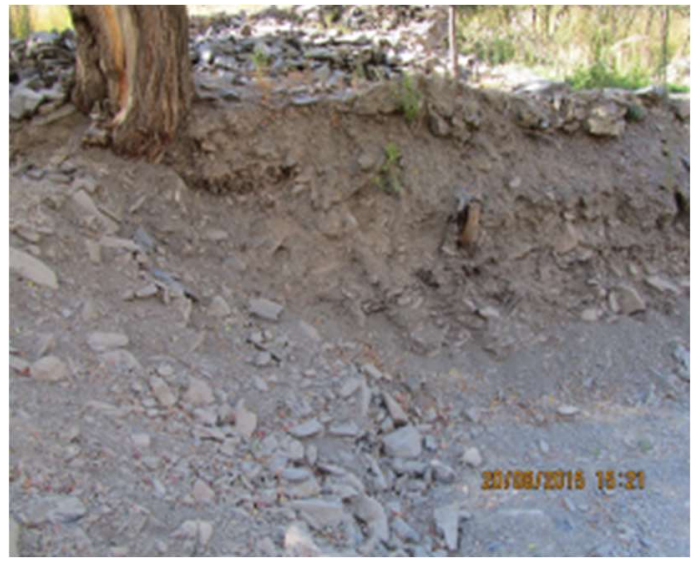

Fig. A.26. Refrigerated sediment sampled No. 2 


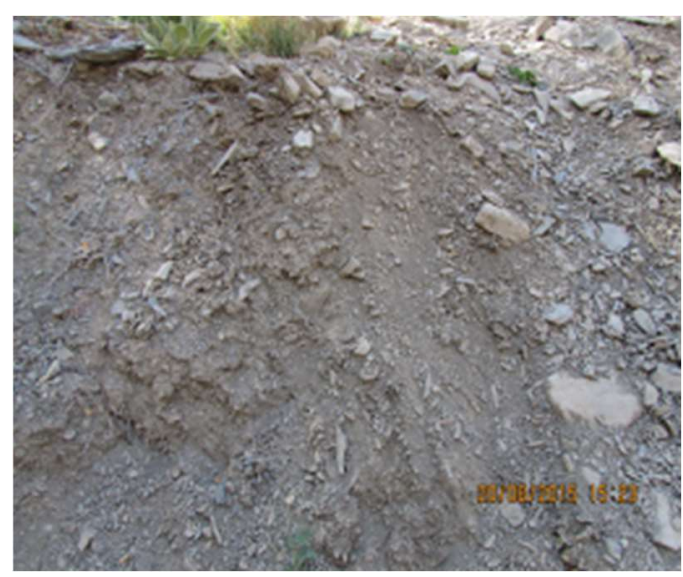

Fig. A.27. Refrigerated sediment sampled No. 3

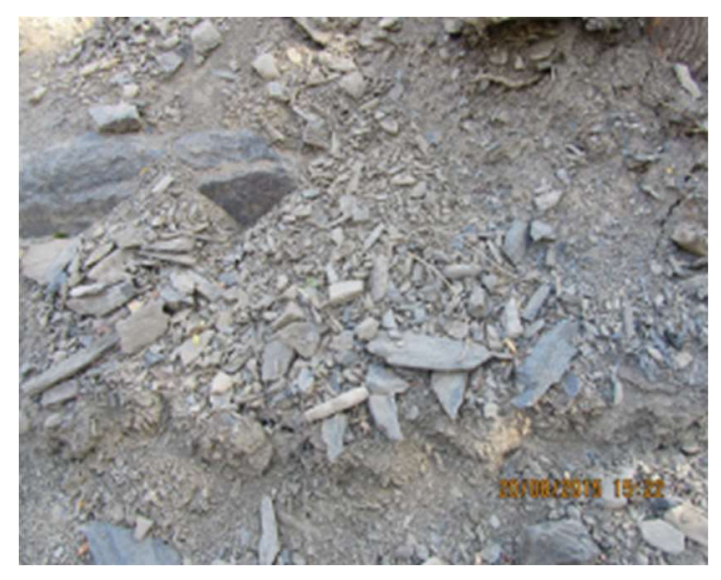

Fig. A.28. Refrigerated sediment sampled No. 4

\subsection{Granulometri examination}

\subsubsection{Sampling points}

\subsubsection{Granulometry (the measurement of the size distribution in a collection of grains)}

Using the measurement of the size distribution in a collection of grains (Granulometry), changes in the diameter of grains and concentration of each of them can be determined and using the size of grains and the accumulative percentage of sediments, the type of sediments can be determined Motamedi $(2005,13)$. In the present study, first of all the special places (sediments which the possibility of their carrying by glaciers is available) were sampled and grains were separated in terms of their different sizes. To do so, firstly using a precise scale, $400 \mathrm{~g}$ of each of sediments were sampled and weighted and then, sediments were dried in the ironing machine at the temperature $105 \mathrm{C}^{\circ}$. Concerning the mixed nature of sediments (fine- and coarse-grained sediments) 10 sieves with 74, 125, 150, 250, 300, 420, 590, 840, 1410, and 2800 microns were selected and to determine the amount of sediments in different diameters, the samples were poured in the biggest sieve (2800 microns) and the vibration machine was run for 15 minutes. Sieves are able to retain those sediments whose diameters is bigger than the hoses of the sieve and send the rest below. After 15 minutes, materials were separated in terms of the size of grains and sieves were weighted again their weight with their numbers were noted. After that, using the Excel software, the chart related to each of the samples was drawn and data were analyzed. By investigating the results of the data, it was concluded that samples indicate the glacial performance in the region under study. Following samples indicate Granulometry of grains in different samples(Fig 29, 30, 31, 32). 


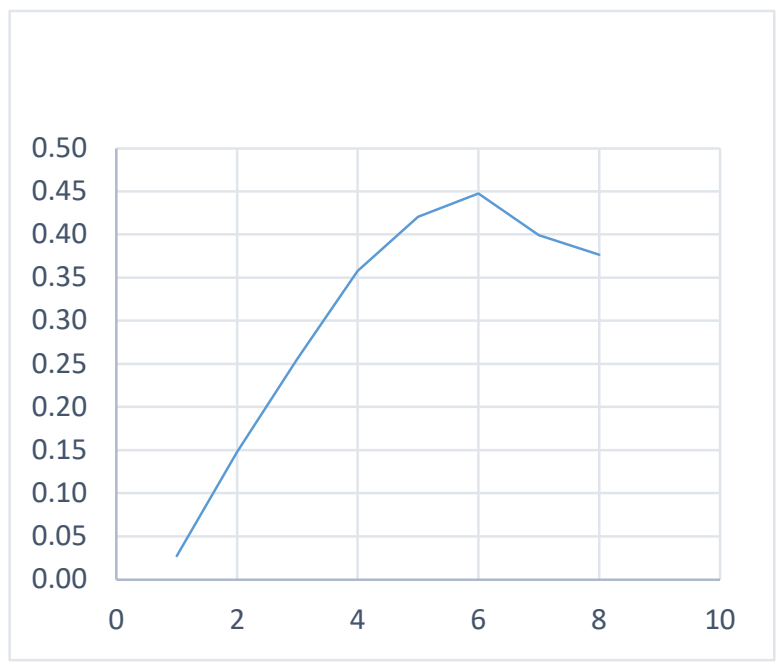

Fig. A.29. sample 1

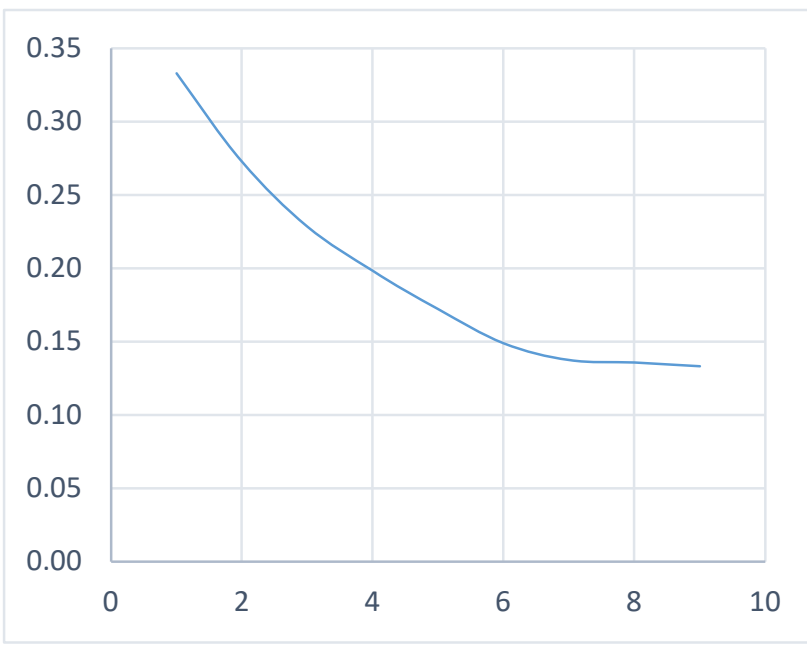

Fig. A.30. sample 2

(The vertical axis indicates the cumulative percentage and the horizontal one indicates the diameter per micron)

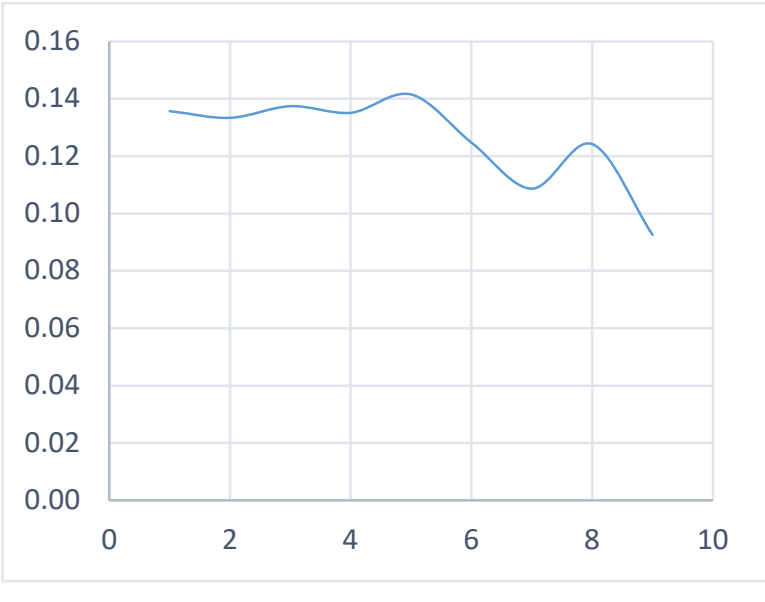

Fig. A.31.sample 3

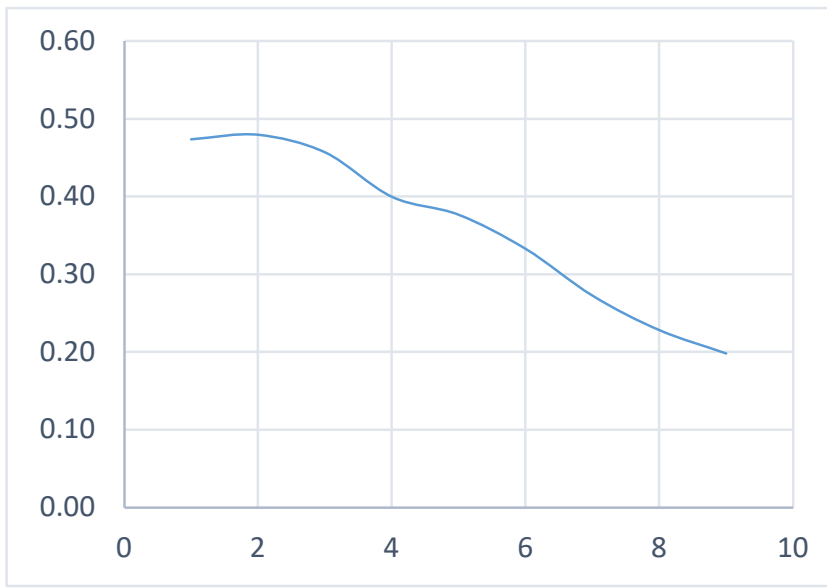

Fig. A.32. sample 4

\subsubsection{Interpretation of Charts}

Based on the calolik Chart, three stages of flow can be identified in relation to the curve process. Curves whose curvature is higher than square diameter indicate that sediment has been impeded by a stream that was unable to carry them, as in example No. 4. Curve whose curvature is lower than square diameter indicates severe river currents. Is, as in Example 3. Curves around the square diameter are the result of sediment flow. Such as river currents, winds and seaside. As in Example 2(Table 2).

Table A.2. Deposits nature of the studied samples

\begin{tabular}{|c|c|c|c|c|c|c|c|c|}
\hline $\begin{array}{c}\text { Sample } \\
\text { No }\end{array}$ & d10 & Q1 & M & D60 & Q3 & So & Qdf & He \\
\hline 1 & 150 & 1300 & 1761 & 2350 & 2650 & 3.93 & 2.84 & 0.64 \\
\hline 2 & 320 & 1630 & 1905 & 2670 & 3000 & 2.54 & 6.55 & 0.36 \\
\hline 3 & 76 & 95 & 114 & 180 & 350 & 3.79 & 4.3 & 0.4 \\
\hline
\end{tabular}




\begin{tabular}{|l|l|l|l|l|l|l|l|l|}
4 & 26 & 81 & 194 & 200 & 700 & 2.15 & 4.05 & 0.2 \\
\hline
\end{tabular}

\subsubsection{Morphoscopy indices}

Morphoscopy operations are conducted on those grains whose thickness is less than $2 \mathrm{~mm}$. therefore, it is better that holes of sieves be between 500 to 700 microns. Samples selected for this aim are washed with hydrochloric acid and hydrogen peroxide in such a way that no impurity be available. From the sieved sediments, 590 micron sediments were selected and prepared for morphoscopy operations and for observing morphoscopy, 100 grains were selected and put on the substantial glass and using morphoscope, each grain was studied separately(table.3).

Table A.3. the results of morphoscopy operations of sediments

\begin{tabular}{|c|c|c|c|c|c|}
\hline \multicolumn{2}{|c|}{ Percentage } & $\begin{array}{c}\text { The number of } \\
\text { experimented } \\
\text { grains }\end{array}$ & $\begin{array}{c}\text { Size of grains per } \\
\text { micron }\end{array}$ & Sample No \\
\cline { 1 - 2 } Debris deposits EN & Water EL & Glacial NU & & 590 & 1 \\
\hline $16 \%$ & $60 \%$ & $24 \%$ & 100 & 590 & 2 \\
\hline $20 \%$ & $42 \%$ & $38 \%$ & 100 & 590 & 3 \\
\hline $31 \%$ & $53 \%$ & $16 \%$ & 100 & 590 & 4 \\
\hline $39 \%$ & $49 \%$ & $12 \%$ & 100 & & \\
\hline
\end{tabular}

\subsubsection{Morphoclimatic zones of study area based on Peltier curve}

According to the Lewis Peltier method, the morphoclimatic zones of the region were identified in both cold and present phases. In fact, in this method, using the polyester diagram (Fig. 33, 34) and the annual temperature and precipitation parameters of the glacial, adjacent glacial, boreal (Tondra and Taiga) oceanic, Selva (rainforest), temperate, savannah, semiarid, And it dried up. By plotting diagrams in the GIS environment and performing geometric correction of its coordinates based on precipitation and temperature, it was combined with current temperature and precipitation maps and glacial period. Temperature and precipitation of pixels and two point layers whose pixel locations were determined using current temperature and precipitation values and cold period and were matched with Peltier diagrams, resulting in current morphoclimatic maps and Quaternary end phase. As shown in Figure 33.

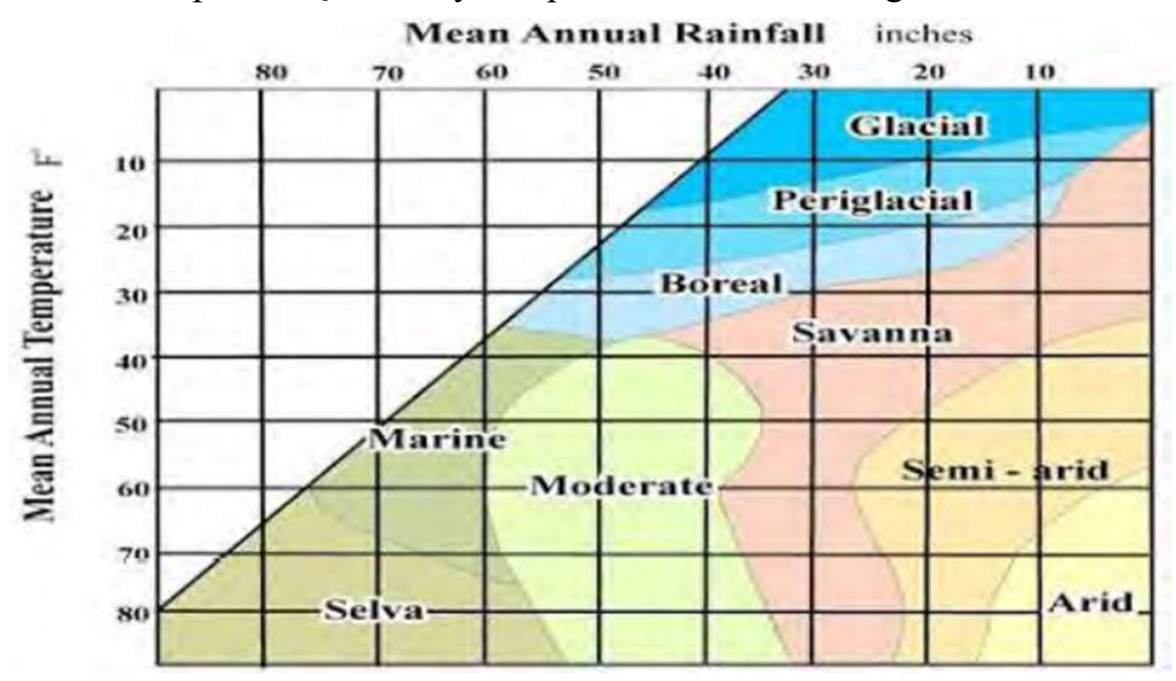

Fig.A. 33. Peltier morfhoclimatic zones diagram (Politer: 1950) 


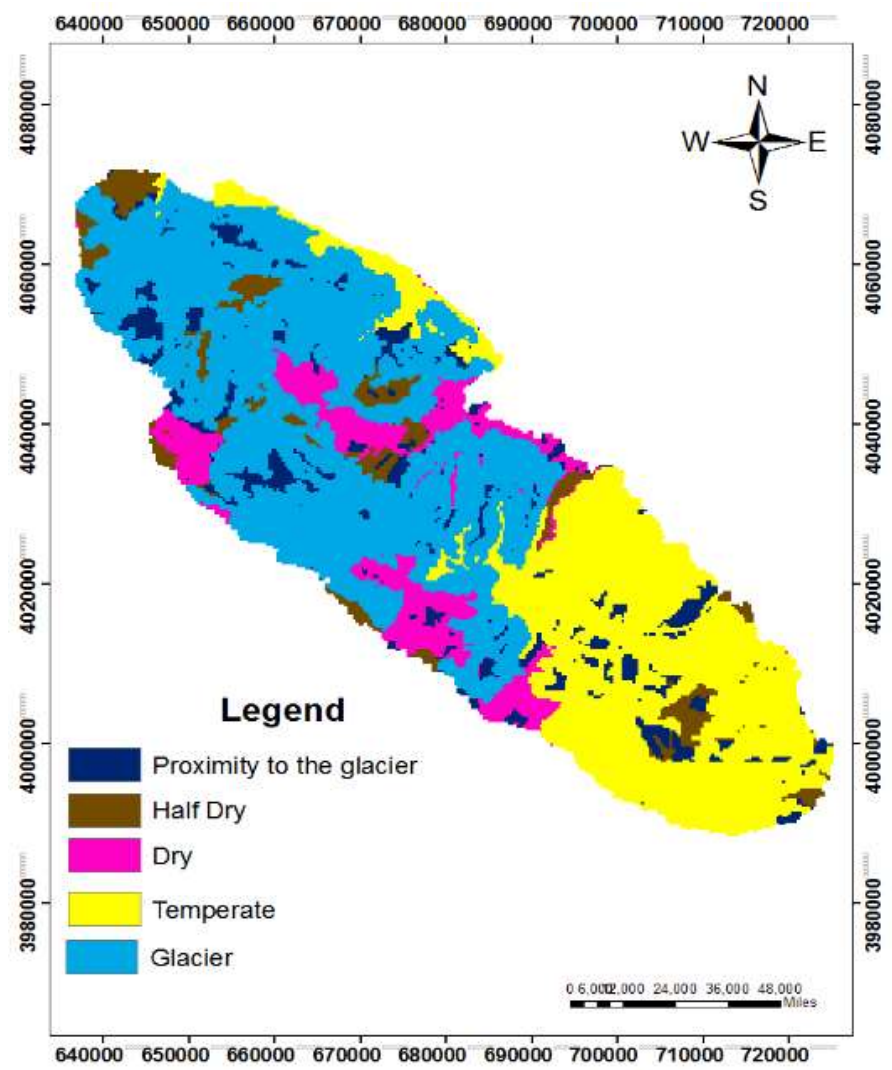

Fig.A. 34. Morphoclimatic zones of the basin at present 


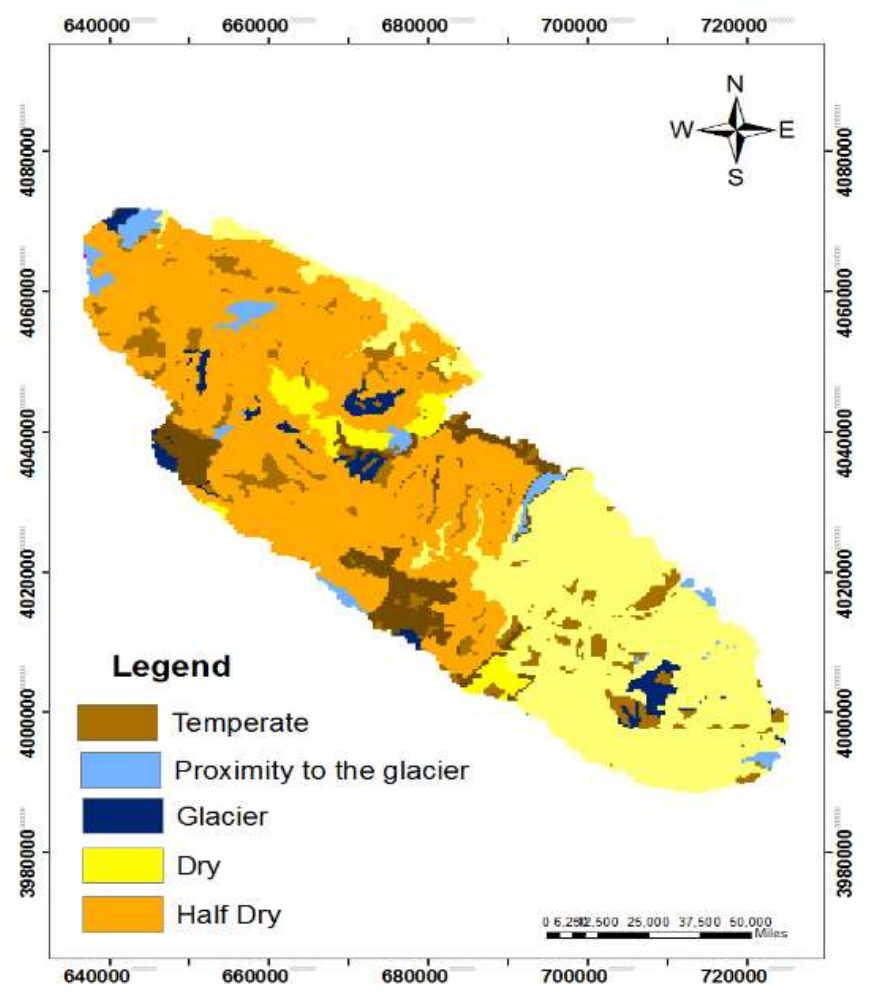

Fig.A. 35. Morphclimatic zones of the basin during the Quaternary period

Climate with its periodical changes during the quaternary period has been the origin of a lot of upheavals in land forms and the formation of human civilizations. From significant characteristics of the quaternary period which have caused its distinction from other geological periods is the advent of human and the other is the advance and retreat of permanent glaciers in high latitudes and heights during glacial and inter-glacial periods. The result of the governance anaglacial periods in Iran is the formation of cold civilization and the domination of and the result of the domination of cataglacial periods was warn civilization. But such an event did not occur alternatively, but the concurrency of these events is considered among exceptional civil characteristics in Iran. From among pieces of evidence which confirms the location of the snow line in the region is the location of cities and villages created in the region. The water-ice balance line in the region is the main factor in creating canons of non-current rural civilization and sometimes small cities. For northern domains of Binalod and the existence of glacial cirques in these heights in the quaternary period as well as the accumulation of snow on these cirques have caused water flows to surrounding rivers and resulted in the evolution of civilization and expansion of the City of Mashhad. The direction of ice in glacial periods fed by the higher snow resources has been able to be flowed hundreds of meter lower than the permanent snow line. Cities established on the mentioned border have particular identity characteristics. The direction of mountains and their heights have great roles in the way of distributing such canons. Dispersion of villages in the region considered previously as near-glacial regions is higher. That is the concentration of villages lower than the permanent snow line is more abundant in such a way that the expansion of civilization in this region follows the movement of glacier tongues. The results of studies conducted on weather and climate conditions of the region in the quaternary period and at the present time indicated that the average annual temperature at the time of domination of glaciers ranges from $6 \mathrm{C}^{\circ}$ in the plain to $-3 \mathrm{C}^{\circ}$ in heights. In addition, the average temperature at the present time ranges from $13 \mathrm{C}^{\circ}$ in the plain to $3 \mathrm{C}^{\circ}$ in heights and it is $7 \mathrm{C}^{\circ}$ colder in the past than in the present time. In case of humidity conditions of the region, in spite of the minimum and maximum precipitation as 630 and $430 \mathrm{~mm}$ in the Pleistocene and 504 and 268 $\mathrm{mm}$ at the present time, and considering morphological evidence and phenomena of the region of climate conditions necessary for constructing them, these results can be obtained that the humidity conditions of 
the region were significant in the past time so that not only the temperature of the past time is $7 \mathrm{C}$ colder, but its precipitation was twice the present time.

\section{Conclusion}

Rural settlements and the spatial expansion of Mashhad are dependent on climate conditions in the quaternary periods. Quaternary climate changes have important effects on displacement and migrations, jobs, residents, and other human activities. Civilization development follows the model of climate changes, i.e. the domination of cold and warm periods in such a way that in Iran, cold periods is concurrent with the time when big and diverse civilizations are shaped and warm periods are concurrent with the limitations and the loss of civil canons. Paleoclimate evaluation of the region based on morphic evidence indicates that warm northern domains have experienced more severe cold than southern domains and the concentration of cirques in northern domains is higher than cirques in the opposite fronts. Another finding of the present study is the identification of direct influence of previous glacial environments and current cold canons on the existing economic and social life. This issue is important form two perspectives: first due to cold climate and long ice periods, in spite of the existence of positive points such as nearness to the north to south communicative network and relative sufficient water resources, the Plain of Mashhad has attracted appropriate population. One of the factors in attraction of population is the domination of cold conditions. Secondly, the direct influence of glacial effects on site selection of settlements is one of the important issues considered by researchers. This city is located in a fertile plain among two mountain ranges filled with water called Hezar Masjed (at north) and Binalod (at south) and beside the Kashf rood River(Fig.36). Gradually, with the integration of Sanabad and Noghan which later became two neighborhoods of Mashhad City, the first core of Mashhad was formed. 


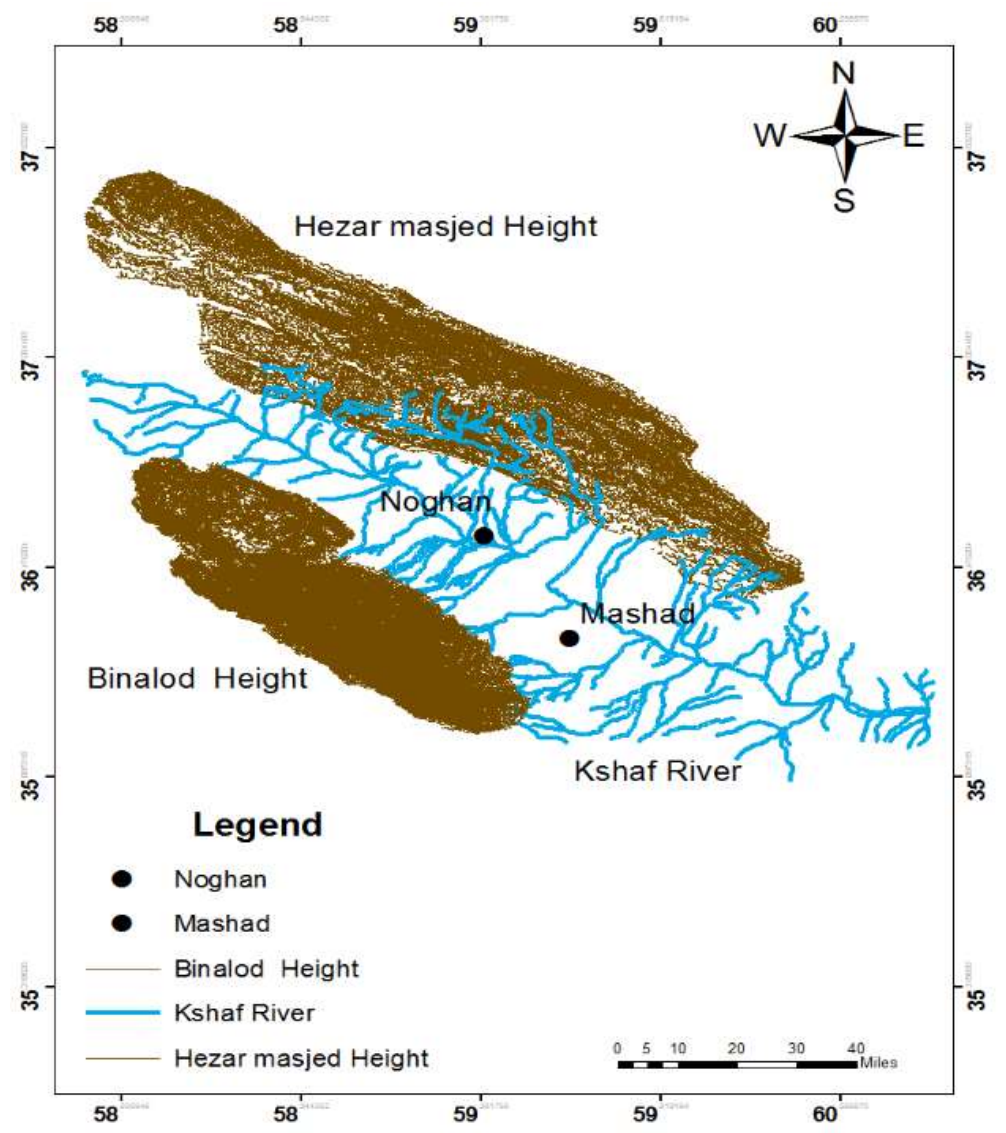

Fig.A. 36. the map of natural formation and location of Mashhad City

Mashhad is a city whose urbanization is not only dependent on the existence of the Kashfroud River, but also glacial movements can be effective in this regard and this is due to the specific topographical conditions and environmental characteristics of the City of Mashhad. Mashhad City is a plain around which there are mountains and hills and in one side of it there is the Kashfroud River. These characteristics has been effective on the geomorphology of the region and the expansion of urbanization of Mashhad City. The existence of 65 small and big cirques is considered as one of the main water resources. Regarding the isothermal map of the past time and the concentration of cirques, it can be said that the region acted as a cold hole or glacial plain in the past and in the quaternary periods, due to environmental humidity and coldness as well as a height higher than $2500 \mathrm{~m}$ covered by mountainous ice, a large resource of water was created there and sometimes this resource moved in the form of mountainous ice and run toward lower regions. By lowering heights and increasing environmental temperature, ice is melted and rivers have more water. The centralized movement of ice with carrying moraine sediments usually cause the creation of till and moraine resources with the capacity of storing sufficient underground water resources. At the beginning, Mashhad Plain was located near a river filled with water, but due to the fact that the Kashf rood River runs in height lower than Mashhad, accessing the water of this river was not possible for people of the city. Therefore, most villages and Noghan and Mashhad themselves, from the beginning to early the present century, mostly use wells for supplying their water. Accordingly, regarding to evidence and results, one of the main factors in formation and development of civilization of Mashhad and rural settlements can be considered as glacial activities and coldness in such a way that the spatial distribution of rural settlements follows exactly the movement and formation of glacier tongues. At the present time, considering the loss of cold conditions of the region compared to the past time, the control of surface water should be conducted 
for developing rural and urban regions. In addition, reconstructing past climate conditions can guide us for investigating climate changes and urbanization, identifying the environment and the expansion of civilization for having more comprehensive knowledge of environmental, cultural, and behavioral features; and be used in different sciences. According to climate change during the Quaternary period and increasing rainfall and temperatures during this period, atmospheric downpours have been snow-covered and accumulated volumes of snow and ice that melted snow and melted ice, and melted water and ice flows. It has been formed into river beds. An example of this is the River Discover, which led to urban civilization in the Quaternary period. This is because most agricultural and habitat beds are created along the rivers. Although in recent years, due to the above graphs, temperature rise and lack of precipitation have been caused, but urban settlements, especially Mashhad, are located on the banks of the Kashaf rood River due to the Quaternary climatic conditions. Based on field observations and laboratory work and sediment screening, we concluded that habitat use was due to Quaternary climatic conditions.

\section{References}

Aarseth, I., Mangerud, J. (1974). Some geological implications of average Quaternary glacial conditions, Quaternary Research, 32(3), 245-261.

Agatova, AR., Nepop ,RK., Slyusarenko, I.Yu., Myglan ,V.S., Nazarov, A.N., Barinov ,V.V. (2014). Glacier dynamics, palaeohydrological changes and seismicity in southeastern Altai (Russia) and their influence on human occupation during the last 3000 years, Quaternary International: 324, 6-19.

Almodarresi, S.A. (2005). nHydro-morphology of Sakhvid Basin of Yazd, MA thesis of University of Isfahan.

Ariai, A., Thibault, C .(1997). Nouvelles Proeoisions apropos de loutillage paleolithique anacien sur galets de khorassan (Iran) paleorient, 3 , 101-8.

Brook, M., Kirkbride, M.P. (2018). Reconstruction and paleoclimatic significance of late Quaternary glaciers in the Tararua Range, North Island, New Zealand, Quaternary International, (470), 53-66.

Delmas, M., Gunnell, Y., Marc Calvet, M. (2015). A critical appraisal of allometric growth among alpine cirques based on multivariate statistics and spatial analysis, Geomorphology, (228), 637652.

Falamaki, M. (1988). The evolution of cities and citizenship in Iran. Tehran, Noghreh, 336.

Fredin, Ola., Bjorn, B., Raymond, E., Louise, H., Oddvar, L., Atle, N., Harald, S. (2013). Glacial Landforms and Quaternary Landscape Development in Norway, Quaternary Geology of Norway, Geological Survey of Norway, Special Publication, (13).

Gachev, E., Stoyanov, K., Giko, A. (2016). Small glaciers on the Balkan Peninsula, State and changes in the last several years, Quaternary International.

Hrton, B. (2004). Human responses to Holocene sea level change in the Persian Gulf by universitiy of Pennsylvania and university of Durham.

Kuffman, j. (1990). Physical Geology, Prentice Hall, New Jersey.

Mindrescu, M., Evans, I.S. (2014). Cirque form and development in Romania: Allometry and the buzzsaw hypothesis, Geomorphology, (208), 117-136.

Motamed A., 2013. Quaternary geography, Tehran, SAMT, 268. 
Nematollahi, F. (2003). Glacial evidence in Iran, Humanities Journal of University of Tabriz, 3, $52-71$.

Pedrami, M .(1982). Pleistocene Glaciation's and Paleoclimate in Iran, Geol, Surv, Iran, Tehran.

Peltier, L.C. (1950). The geographic cycle in periglacial regions as it is related to climatic geomorphology. Annals of the association of American Geographers, 40(3), 214-236.

Peru Jeffrey, T., Bury Bryan, G., Mark Jeffrey, M., McKenzie Adam, F., Baraer Kyung, M. (2014). In Huh Marco Alfonso Zapata Luyo Ricardo Jesús Gómez López, Glacier recession and human vulnerability in the Yanamarey watershed of the Cordillera Blanca, 105, 179-206.

Ramesh, M.H., Abbasi, A., Montazeri, M. (2000). Natural History evolution and the formation of civilization on the edge of the Zayandehrood River, 11, 116-101.

Ramesht, M. H. (2002). Glacial evidence in Zofreh of Isfahan, Research project of University of Isfahan.

Ramesht, M. H. (2009). Ice in fire: glacial evidence in Bam, Geographical Research Journal, 33, 144-129.

Ramesht, M. H. (2011). Detecting traces of glaciers, Case Study: Tigaran Basin of Mahan, Geography and Environmental Planning, 22(2), 59-78.

Ridhima, S., Arabinda, M., Navarun, V., Suruchi, B. (2015). Adaptation policy and practice in densely populated glacier-fed river basins of South Asia: a systematic review, Reg Environ Change, 15, 825-836.

Rob, H., Dott, Ir. (1981). Pleistocene Glaciations and the Rise of Man, Third Edition Evolution OF the Earth.

Sorg, A., Bolch, T., Stoffel, M., Solomina, O., Beniston, M. (2012). Climate change impacts on glaciers and runoff in Tien Shan (Central Asia), Nat, Clim, Change, 2, 725-731.

Takeuchi, N., Fujita, K., Aizen, V. (2014). Chiyuki Narama Yusuke Yokoyama e, Sachiko Okamoto b, Kazuhiro Naoki f, Jumpei Kubota. The disappearance of glaciers in the Tien Shan Mountains in Central Asia at the end of Pleistocene, Quaternary Science Reviews ,103, 26-33.

Vaziri, F. (2003). Applied hydrology in Iran. $2^{\text {nd }}$ vol. identifying glaciers in Iran. Publication of Management and Planning Organization of Iran, 430.

Vita Finzi, C. (1980). Surface finds from Iranian Makran, 18, 149-55.

Wright, H.E. (1963). Climatic Chanche and Plant Domesticationin The Zagros Mountains, journal of Persian studies, 145-148.

Yesilyurt, S., Akçar, N., Dogan, U., Yavuz, V., Ivy- Ochs, S., Vockenhuber, C., Schlüchter, C. (2016). Extensive Quaternary glaciations in eastern Turkey, In EGU General Assembly Conference Abstracts, (18), 170-183.

Yixin, Ch., Gengnian, L., Beibei , L., Yingkui, L., Qing, L., Yesong, H., Weilin Yang, Z. (2018). Late Quaternary glaciations in the Cogarbu valley, Bhutanese Himalaya, URNAL OF QUATERNARY, 34(1), 0267-8179. 
